\title{
Neuromyelitis optica Neuromyelitis optica
}

Florence Pache, Brigitte Wildemann, Friedemann Paul, Sven Jarius

\author{
Die Neuromyelitis optica mündet ohne Therapie häufig in irreversiblen neuro- \\ logischen Behinderungen bis hin zu Rollstuhlpflichtigkeit und Erblindung. Dieser \\ Beitrag vermittelt die nötigen Kenntnisse in Diagnostik, Pathogenese und \\ Therapie, um unter verschiedensten Voraussetzungen mit einer frühzeitigen und \\ konsequenten immunsuppressiven Behandlung weitere Schübe mit der Gefahr \\ einer schweren Behinderung zu verhindern.
}

\section{Einleitung}

Die NMO (Neuromyelitis optica) ist eine oft schwer verlaufende Autoimmunerkrankung des zentralen Nervensystems, die eine rasche und konsequente Behandlung erfordert [1,2]. Entzündungen des Rückenmarks und des Sehnervs verlaufen rezidivierend und nicht selten auch fulminant. Ohne Behandlung führen sie häufig zu irreversiblen neurologischen Behinderungen bis hin zu Rollstuhlpflichtigkeit und Erblindung. In einem nicht unbeträchtlichen Teil der Fälle ist der Hirnstamm oder das Zwischenhirn beteiligt. Supratentorielle Hirnläsionen sind zwar zu Beginn der Erkrankung selten, entwickeln sich aber bei bis zu $80 \%$ der Fälle im weiteren Krankheitsverlauf und sind vor allem bei Erwachsenen meist auf den ersten Blick asymptomatisch [3,4]. Eine frühzeitige und konsequente immunsuppressive Behandlung kann weitere Schübe mit dem Risiko einer schweren Behinderung in vielen Fällen verhindern.

Patienten mit rein optikospinaler Manifestation wurden bereits im frühen 19. Jahrhundert beschrieben [5 - 13]. Im Jahr 1894 veröffentlichten Eugène Devic (18581930) und Fernand Gault (1873-1936) eine grundlegende Übersichtsarbeit zum Thema. Im Laufe der Jahre unterlagen die diagnostischen Kriterien der NMO zahlreichen Wandlungen. Besondere Bedeutung kommt historisch den von Wingerchuk 1999 formulierten Kriterien zu, die internationale Anerkennung fanden [14]. Diese legten den Fokus nicht nur auf die Schubschwere und den Liquorbefund, sondern vor allem auf die spinalen und kranialen MRT-Befunde [14]. Es folgte die Entdeckung direkt pathogener IgG-Antikörper (Immunglobulin-G-Antikörper), sog. NMO-lgG, gegen das astrozytäre Wasserkanalprotein AQP4 (Aquaporin-4) [15-20]. Da diese Antikörper bei bis zu $80 \%$ der NMO-Patienten nachweisbar sind, rückte die serologische Diagnostik in den Mittelpunkt [21,22]. Dies führte 2006 zur Revision der diagnostischen Kriterien [23], die nun eine akute Myelitis und eine Optikus- neuritis (nicht notwendigerweise gleichzeitig) sowie mindestens 2 der folgenden 3 unterstützenden Kriterien verlangten:

$\begin{array}{ll}\text { ABKÜRZUNGEN } & \\ \text { ACE } & \text { angiotensinkonvertierendes Enzym } \\ \text { ADEM } & \text { akute disseminierte Enzephalomyelitis } \\ \text { ADH } & \text { antidiuretisches Hormon } \\ \text { ANCA } & \text { antineutrophile zytoplasmatische Antikör- } \\ & \text { per } \\ \text { APRIL } & \text { proliferationsinduzierender Ligand } \\ \text { AQP4 } & \text { Aquaporin-4 } \\ \text { BAFF } & \text { B-Zell-aktivierender Faktor } \\ \text { CXCL } & \text { C-X-C-Motiv-Ligand } \\ \text { DNA } & \text { Desoxyribonukleinsäure } \\ \text { EDSS } & \text { Expanded Disability Status Scale } \\ \text { ELISA } & \text { Enzyme-linked Immunosorbent Assay } \\ \text { FSME } & \text { Frühsommer-Meningoenzephalitis } \\ \text { HIV } & \text { humanes Immundefizienzvirus } \\ \text { HTLV } & \text { humanes T-lymphotropes Virus } \\ \text { Ig } & \text { Immunglobulin } \\ \text { IL } & \text { Interleukin } \\ \text { LETM } & \text { Longitudinal extensive transverse Myelitis } \\ \text { MOG } & \text { Myelin-Oligodendrozyten-Glykoprotein } \\ \text { MRZ-Reaktion } & \text { Masern-Röteln-Zoster-Antikörper-Reaktion } \\ \text { NMDAR } & \text { N-Methyl-D-Aspartat-Rezeptor } \\ \text { NMO } & \text { Neuromyelitis optica } \\ \text { NMOSD } & \text { Neuromyelitis optica Spectrum Disorders } \\ \text { PML } & \text { progressive multifokale Leukenzephalopa- } \\ \text { thie } & \text { systemischer Lupus erythematodes } \\ \text { SLE } & \text { ständige Impfkommission des Robert- } \\ \text { STIKO } & \text { Toch-Instituts } \\ \text { TNF } & \text { Varizella-zoster-Virus } \\ \text { ZBA } & \end{array}$


- Es liegt eine kontinuierliche Myelonläsion über mindestens 3 Wirbelkörpersegmente vor (sog. LETM [Longitudinal extensive transverse Myelitis]).

- Das zerebrale MRT erfüllt bei Erkrankungsbeginn nicht die Kriterien für eine multiple Sklerose nach Paty [24] (d. h. weniger als 4 Marklagerläsionen oder weniger als 3, wenn mindestens eine periventrikulär ist, oder normales MRT).

- Es besteht ein positiver NMO-IgG/AQP4-IgGSerostatus.

Der Nachweis von AQP4-Antikörpern erleichterte die Diagnose und ermöglichte unter Beibehaltung der Erfordernisse einer Myelitis und Optikusneuritis nunmehr die Diagnosestellung auch bei gleichzeitig vorliegenden Hirnläsionen. Im Jahr 2007 wurde der Begriff „NMOSD“ (Neuromyelitis optica Spectrum Disorders) als zusammenfassende Bezeichnung der NMO und ihrer AQP4-IgG-positiven limitierten Formen (isolierte Optikusneuritis, isolierte LETM u.a.) eingeführt [25]. Es zeigte sich dann, dass AQP4-IgG-seropositive Patienten hinsichtlich klinisch-radiologischer Parameter sowie auch hinsichtlich Prognose und Therapie eine abgrenzbare Subgruppe darstellen [1]. Dies führte zur bislang letzten Revision der Diagnosekriterien im Jahr 2015. Diese tragen nicht nur dem erweiterten klinischen Spektrum der NMO Rechnung, sondern berücksichtigen auch den Umstand, dass Seropositivität für AQP4-IgG eine einheitliche Pathophysiologie impliziert. Die neuen Diagnosekriterien verwenden den Terminus „NMOSD“ als Obergriff und unterscheiden nunmehr zwischen „NMOSD mit AQP4-IgG“ und „NMOSD ohne AQP4-IgG oder mit unbekanntem AQP4-IgG-Status“ ( $\triangleright$ Tab. 1) [26, 27].

\section{DEFINITION}

Sofern nicht anders angegeben, wird im Folgenden in Übereinstimmung mit aktuellen internationalen Konsensusempfehlungen [26] der Begriff „NMOSD“ verwendet, der sich sowohl auf die NMO als auch auf ihre limitierten Formen bezieht.

\section{Epidemiologie}

Die Prävalenz der NMOSD schätzt man in westlichen Ländern auf 1-10 pro 100000. Dabei sind bevölkerungsbasierte Studien nur für einige Länder bzw. Regionen verfügbar [28 - 30]. International variiert die Prävalenz erheblich, möglicherweise auch genetisch determiniert. Die in Asien im Vergleich zur konventionellen multiplen Sklerose relativ häufige sog. optikospinale multiple Sklerose wurde als mehrheitlich mit AQP4-lgG assoziiert erkannt und unterscheidet sich in diesen Fällen nicht von der konventionellen NMO [26, 28, 31].

\section{Merke}

Wie bei anderen Autoimmunerkrankungen sind auch bei der NMO Frauen häufiger betroffen und zwar im Verhältnis von ca. 9:1 in AQP4-IgG-positiven Fällen und von ca. 3:1 in den selteneren AQP4-IgG-negativen Fällen [3, 32].

Nach bisherigem Wissen ist ein Fortschreiten der Behinderung bei NMOSD durch Häufigkeit und Schweregrad der akuten Erkrankungsschübe bestimmt: Eine schubunabhängige, schleichende Progression gilt im Gegensatz zur multiplen Sklerose als untypisch [3335]. Der mediane Erkrankungsbeginn liegt zwischen dem 30. und 40. Lebensjahr [3], Erstmanifestationen im Kindesalter und im Senium sind allerdings beschrieben $[36,37]$. Häufig sind weitere Autoimmunerkrankungen (vor allem Myasthenia gravis [38], SLE [systemischer Lupus erythematodes] und Sjögren-Syndrom) als Komorbiditäten und Korrelat einer autoimmunen Prädisposition mit der AQP4-IgG-positiven NMOSD vergesellschaftet $[1,39,40]$.

\section{Diagnostik}

\section{Klinische Symptome}

Klinisch manifestiert sich die Erkrankung meist als

- akute Myelitis mit sensiblen, motorischen und/oder autonomen Reiz- oder Ausfallerscheinungen bis hin zum vollständigen sensomotorischen Querschnitt,

- als akute Optikusneuritis mit visuellen Defiziten bis hin zur kompletten, mitunter beidseitigen Erblindung oder

- als akute Hirnstammenzephalitis, die häufig die Area postrema der Medulla oblongata betrifft und durch unstillbaren Schluckauf und/oder unstillbares Erbrechen gekennzeichnet ist [1,3,41-47].

Letzteres wurde in der Vergangenheit bei jungen Patienten bisweilen (mit zum Teil fatalem Ausgang) als Anorexie bzw. Bulimie fehlgedeutet. Zu den am meisten gefürchteten Komplikationen zählt die neurogene respiratorische Insuffizienz infolge hoher zervikaler Myelitiden oder Hirnstammenzephalitiden. Weitere, relativ seltene Manifestationen sind die Narkolepsie [48], das Syndrom der inadäquat hohen ADH-Sekretion (Sekretion des antidiuretischen Hormons) infolge von dienzephalen Läsionen sowie enzephalitische Syndrome einschließlich epileptischer Anfälle. Diese wurden vor allem bei Kindern beschrieben [49,50]. Eine Einschränkung der Lebensqualität können auch neuropathische Schmerzen und tonische Hirnstammspasmen sowie Blasenstörungen, Fatigue, Depressionen, Schlafstörungen und möglicherweise auch kognitive Störungen bedeuten [51 - 59]. 
- Tab. 1 Internationale Konsensuskriterien für die Diagnose von NMOSD nach Wingerchuk u. Mitarb. [26].

\begin{tabular}{|c|c|}
\hline NMOSD mit AQP4-IgG & NMOSD ohne AQP4-IgG \\
\hline $\begin{array}{l}\text { positiver AQP4-IgG-Test mit der besten verfügbaren } \\
\text { Testmethode (ZBA dringend empfohlen) }\end{array}$ & $\begin{array}{l}\text { negativer AQP4-IgG-Test mit der besten verfügbaren Testmethode (ZBA } \\
\text { dringend empfohlen) oder unbekannter AQP4-IgG-Serostatus }\end{array}$ \\
\hline $\begin{array}{l}\text { mindestens eines der folgenden klinischen bzw. klinisch- } \\
\text { radiologischen Syndrome: } \\
\text { " akute Optikusneuritis } \\
\text { " akute Myelitis } \\
\text { " akutes Area-postrema-Syndrom* } \\
\text { " akutes sonstiges Hirnstammsyndrom } \\
\text { " akutes dienzephales Syndrom oder symptomatische } \\
\text { Narkolepsie } \\
\text { + periependymale (III. Ventrikel) } \\
\text { oder Hypothalamus- bzw. Thalamusläsion in der MRT } \\
\text { " akutes zerebrales Syndrom } \\
\text { + periependymale (Seitenventrikel) und extensive Hirnläsion } \\
\text { in der MRT } \\
\text { oder langstreckige (>1⁄2 Länge), diffuse, heterogene oder } \\
\text { ödematöse Balkenläsion } \\
\text { oder langstreckige Tractus-corticospinalis-Läsion (ein- oder } \\
\text { beidseitig) einschließlich Capsula interna und Hirnschenkel } \\
\text { oder große, konfluierende (ein- oder beidseitige) Läsion } \\
\text { subkortikal oder im tiefen Marklager }\end{array}$ & $\begin{array}{l}\text { mindestens } 2 \text { (räumliche Dissemination) der folgenden klinisch-radiologischen } \\
\text { Syndrome (nicht notwendigerweise gleichzeitig), davon mindestens eines } \\
\text { Optikusneuritis, Myelitis oder Area-postrema-Syndrom: } \\
\text { - akute Optikusneuritis } \\
\text { + langstreckige N.-opticus-Läsion ( } \geq \text { Hälfte des Sehnervs) oder Chiasma- } \\
\text { beteiligung (T2w oder T1w mit Kontrastmittel) in der N.-opticus-MRT } \\
\text { oder keine oder nur unspezifische Marklagerläsionen in der zerebralen MRT } \\
\text { - akute Myelitis } \\
\text { + langstreckige Myelonläsion ( } \geq 3 \text { Wirbelkörpersegmente; sog. LETM) } \\
\text { oder langstreckige Myelonatrophie ( } \geq 3 \text { Wirbelkörpersegmente) bei } \\
\text { Patienten mit passender Anamnese für eine akute Myelitis in der } \\
\text { Vorgeschichte } \\
\text { - akutes Area-postrema-Syndrom* } \\
\text { + Beteiligung der dorsalen Medulla oblongata bzw. Area postrema in der } \\
\text { MRT, isoliert oder in direkter Fortsetzung einer Hirnstamm- oder } \\
\text { Myelonläsion } \\
\text { " akutes sonstiges Hirnstammsyndrom } \\
\text { + periependymale Läsion (IV. Ventrikel) in der MRT } \\
\text { - akutes dienzephales Syndrom oder symptomatische Narkolepsie } \\
\text { + periependymale (III. Ventrikel) } \\
\text { oder Hypothalamus- bzw. Thalamusläsion in der MRT } \\
\text { " akutes zerebrales Syndrom } \\
\text { + periependymale (Seitenventrikel) und extensive Hirnläsion in der MRT } \\
\text { oder langstreckige (>1/2 Länge), diffuse, heterogene oder ödematöse } \\
\text { Balkenläsion } \\
\text { oder langstreckige Tractus-corticospinalis-Läsion (ein- oder beidseitig) } \\
\text { einschließlich Capsula interna und Hirnschenkel } \\
\text { oder große, konfluierende (ein- oder beidseitige) Läsion subkortikal oder im } \\
\text { tiefen Marklager }\end{array}$ \\
\hline alternative Diagnosen ausgeschlossen & alternative Diagnosen ausgeschlossen \\
\hline
\end{tabular}

\section{Paraklinische Befunde}

\section{Serologie}

IgG-Antikörper gegen AQP4 sollten im Serum bestimmt werden. Eine Liquorpunktion allein zum Zwecke der AQP4-Antikörper-Bestimmung ist in der Regel nicht erforderlich, da der Antikörper vor allem extrathekal produziert wird [60-63]. Die zusätzliche Bestimmung von IgM-Antikörpern erhöht die Sensitivität nicht und ist methodisch problematisch [64].

Etwa $10-20 \%$ aller NMO-Patienten sind jedoch auch bei Verwendung moderner ZBA persistierend negativ für AQP4-IgG. In einer aktuellen multizentrischen Kohortenstudie [69] waren

- bei ca. 13\% der AQP4-IgG-negativen Patienten mit langstreckiger Myelonläsion über 3 und mehr Wirbelkörpersegmente,

- bei $22 \%$ der AQP4-IgG-negativen Patienten mit rekurrierender Optikusneuritis und

- bei $41 \%$ der AQP4-IgG-negativen Patienten mit Optikusneuritis und Myelitis

\section{PRAXISTIPP}

Empfohlen wird die Verwendung von sog. ZBA (zellbasierten Assays). Als Testsubstrat kommen dabei mit humanem AQP4 transfizierte humane embryonale Nierenzellen (HEK293-Zellen) und mock-transfizierte (mit einem leeren Vektor transfizierte) HEK293-Kontrollzellen zum Einsatz $[62,63,65]$. Andere Assays (ELISA [Enzyme-linked Immunosorbent Assay], Radioimmunopräzipitation, Immunfluoreszenz) haben in der Regel eine geringere Sensitivität und/oder Spezifität und sollten daher eher nicht mehr oder nur noch als Bestätigungstests verwendet werden $[2,20$, 66 -68]. Für einen ausführlichen Vergleich der Sensitivitäten und Spezifitäten der derzeit verfügbaren Tests sei auf eine kürzlich erschienene Übersichtsarbeit verwiesen [67]. 
IgG-Antikörper gegen MOG (Myelin-Oligodendrozyten-Glykoprotein) nachweisbar. Die pathogenetische und klinische Relevanz dieser Antikörper wird gegenwärtig intensiv erforscht (s.u. und [69-79]). Eine Bestimmung von MOG-IgG bei Patienten mit AQP4-Antikörper-negativer NMOSD ist gerechtfertigt, wenn ausreichend sensitive und spezifische Assays zum Einsatz kommen.

Wie die AQP4-IgG-positive NMOSD gilt auch die MOGIgG-positive Enzephalomyelitis inzwischen als immunpathologisch von der klassischen multiplen Sklerose abzugrenzende Erkrankung. Phänotypisch weisen AQP4-NMOSD, MOG-IgG-positive Enzephalomyelitis und multiple Sklerose jedoch zahlreiche Übereinstimmungen auf $[76,80]$. Die Häufigkeit AQP4-IgG- und MOG-IgG-doppelt-positiver Fälle ist umstritten [81]. Eine aktuelle multizentrische Studie fand unter 83 AQP4-IgG-positiven und 50 MOG-IgG-positiven Patienten keine doppelt positiven Fälle [69].

Bei einmaliger Bestimmung erlauben die Antikörpertiter keine direkten Rückschlüsse auf die Krankheitsaktivität. Sehr engmaschige Titerbestimmungen wären prinzipiell zur Therapiesteuerung sinnvoll einsetzbar [82], sind aber nicht die Regel, weil sie teuer und nicht praktikabel sind. Die AQP4- und MOG-IgG-Serumtiter sind je nach Therapiestatus und Krankheitsaktivität erheblichen Schwankungen unterworfen. Deshalb sollten zum Ausschluss falsch-negativer Befunde seronegative Patienten im späteren Erkrankungsverlauf erneut getestet werden, insbesondere in therapiefreien Intervallen und im akuten Krankheitsschub. Auch sollte die Testung nach Möglichkeit generell vor Beginn einer Immuntherapie durchgeführt werden, insbesondere vor einer Behandlung mit Plasmapherese oder Immunadsorption.

\section{Sonstige Blutuntersuchungen}

Um Differenzialdiagnosen auszuschließen, um koexistierende Autoimmunerkrankungen (häufig bei AQP4IgG-positiver NMOSD) rechtzeitig zu erkennen sowie als Basisuntersuchung vor Therapiebeginn sind folgende Blutuntersuchungen empfehlenswert:

- Differenzialblutbild

- Blutsenkungsgeschwindigkeit

- Gerinnungsstatus

- Glukosekonzentration

- rheumatologische Basisdiagnostik:

- antinukleäre Antikörper und Profil der antinukleären Antikörper einschließlich Anti-Doppelstrang-DNA-Antikörper (DNA = Desoxyribonukleinsäure)

- ANCA (antineutrophile zytoplasmatische Antikörper)

- Kardiolipinantikörper

- Rheumafaktoren
- bei Verdacht auf ein Sjögren-Syndrom auch bei negativem Befund der antinukleären Antikörper SS-A(Ro)-Antikörper

Außerdem ist - wie auch bei Verdacht auf eine Sarkoidose [83] - eine augenärztliche Untersuchung indiziert. Bei Verdacht auf eine begleitende Myasthenia gravis ist ein serologisches Screening auf Azetylcholinrezeptor-, Titin- und ggf. MuSK- und LRP4-Antikörper im Serum angezeigt. Zum Ausschluss einer funikulären Myelose sollte die Vitamin-B12-Konzentration (und ggf. Folsäure) im Serum bestimmt werden [84], bei niedrig-normalen Werten zusätzlich Methylmalonsäure sowie Holotranscobalamin. Weitere Tests der neurologischen Basisdiagnostik können je nach Fragestellung eine Borrelien- und Treponemenserologie, paraneoplastische Antikörper sowie, sofern eine Sarkoidose differenzialdiagnostisch in Erwägung gezogen wird, den Iöslichen IL-2-Rezeptor (Interleukin-2-Rezeptor), Neopterin und das ACE (das angiotensinkonvertierende Enzym) umfassen. Insbesondere bei myelitischer Präsentation ist auch eine Bestimmung des Serum-VitaminD-Spiegels indiziert. Ein Vitamin-D-Mangel ist nämlich ein Risikofaktor für weitere Rezidive [85]. Deshalb sollte Vitamin D ggf. substituiert werden.

\section{Liquordiagnostik}

Die Liquordiagnostik hilft, zwischen NMOSD und multipler Sklerose zu unterscheiden. Bei NMO-Patienten finden sich häufig folgende Befunde $[60,86,87]$ :

- normale Zellzahl in Remissionsphasen und leichte bis mäßige Pleozytose (gelegentlich aber auch mehr als 300 Zellen $/ \mu \mathrm{l}$ ) im Schub mit oft granulozytärem Anteil (Neutrophile, seltener auch Eosinophile)

- pathologisch erhöhter Liquor/Serum-Albuminquotient als Korrelat einer Störung der Blut-LiquorSchranke (in ca. $50 \%$ der Fälle vorliegend)

- meist fehlende oder nur vorübergehend vorhandene liquorspezifische oligoklonale Banden (nur in ca. 20-30\% der NMOSD-Proben und oft nur während akuter Attacken, aber persistierend bei mehr als $95 \%$ der Multiple-Sklerose-Proben nachweisbar)

- mehrheitlich unauffällige Liquor/Serum-IgGQuotientenwerte

- keine oder nur monospezifische MRZ-Reaktion (Masern-Röteln-Zoster-Antikörper-Reaktion)

\section{Magnetresonanztomografie}

Bei Verdacht auf NMOSD sollten Aufnahmen der gesamten Neuroachse (zerebrale und spinale MRT) einschließlich kontrastmittelgestützter Sequenzen angefertigt werden [1].

In der spinalen MRT sind bei NMOSD-Myelitis langstreckige T2w hyperintense Signalanhebungen charakteristisch, die sich über 3 oder mehr vertebrale Segmente erstrecken ( $\triangleright$ Abb.1). Die Läsionen können in axialen 
Sequenzen den kompletten Myelonquerschnitt einnehmen und sind ansonsten mehrheitlich zentral gelegen. Teilweise kommen zentralnekrotische Areale und Kavitationen vor $[4,88]$. Als sehr charakteristisch gelten sog. Bright spotty Lesions (zentral im Myelon gelegene und in T2w Sequenzen liquorisointense Läsionen) [89]. Allerdings können bei NMOSD auch kurzstreckige Signalveränderungen im Myelon vorkommen-je nach Zeitpunkt der MRT-Diagnostik bezogen auf den Beginn der klinischen Symptome [90, 91]. In Remission finden sich oft langstreckige atrophe Areale. Gegenwärtig wird diskutiert, ob es bei NMOSD gelegentlich auch unabhängig von klinischen Myelitisepisoden bzw. spinalen entzündlichen Läsionen zu einer Atrophie des Rückenmarks kommen kann [92].

Zerebrale kontrastmittelaufnehmende symptomatische Läsionen sind deutlich seltener als bei der multiplen Sklerose. Als sehr charakteristisch für NMOSD gelten wolkige, unscharf begrenzte Läsionen (sog. Cloudlike Enhancement [93]) sowie eine lineare Kontrastmittelaufnahme nahe dem Ependym der Seitenventrikel (sog. Pencil-thin Enhancement [94]). Supratentorielle zerebrale Läsionen sind bei Erkrankungsbeginn eher ungewöhnlich, treten jedoch bei bis zu 80 \% der Patienten im weiteren Krankheitsverlauf auf [4]. Meist handelt es sich um klinisch stumme Zufallsbefunde. Außerhalb der weiter unten beschriebenen Regionen sind sie eher unspezifisch lokalisiert und imponieren meist als punktförmige kleine Läsionen $[95,96]$. Anders als viele Multiple-Sklerose-Läsionen sind sie nicht ovalär und ohne zentrale Vene sowie ohne Äquivalent in den T1w Schichten (keine sog. Black Holes) [89, 90]. Im Gegensatz zur multiplen Sklerose sind bei NMOSD bisher keine kortikalen Läsionen bildgebend nachgewiesen worden [89, 90]. Bislang gibt es auch keine überzeugenden Belege einer globalen Hirnatrophie oder einer Atrophie der grauen Substanz $[4,97,98]$.

\section{Merke}

Wichtig ist, dass zerebrale Läsionen eine NMOSD keinesfalls ausschließen und in typischen Lokalisationen (Thalamus, Hypothalamus und Hirnstamm, vor allem in der Area postrema und häufig periependymal) die Diagnose von NMOSD sogar unterstützen.

Daher finden sie auch in den aktuellen diagnostischen Kriterien Erwähnung (s. > Tab.1). Im Verlauf der Erkrankung können bei etwa 15-20\% der NMOSD-Patienten die Barkhof-Kriterien der multiplen Sklerose im MRT-Bild erfüllt sein [99]. Eine eingehende Diskussion der konventionellen MRT-Charakteristika sowie Befunde aus neueren MRT-Verfahren bei NMOSD finden sich in thematischen Schwerpunktartikeln $[4,100]$.
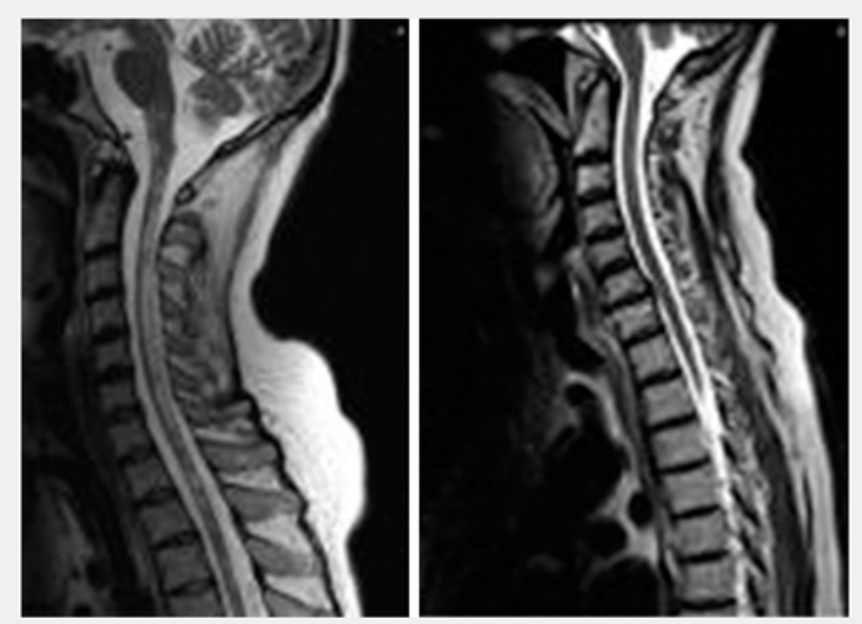

- Abb. 1 Langstreckige, zusammenhängende Myelitis bei AQP4-IgGpositiver NMO. a Patient 1. b Patient 2.

Typische Befunde bei akuter Optikusneuritis sind eine Signalsteigerung in fettunterdrückten T2w Sequenzen und eine Kontrastmittelanreicherung innerhalb des Sehnervs in T1w Sequenzen. Als unterstützend für die Diagnose einer NMOSD gelten insbesondere die Beteiligung beider Nn. optici, der bevorzugte Befall der hinteren Sehnervensegmente mit Ausdehnung bis in das Chiasma opticum sowie auch ausgedehnte, mehr als die Hälfte des Sehnervs betreffende Läsionen [1,26, 73, 101]. Allerdings finden sich ähnliche Befunde wohl auch bei MOG-IgG-positiver Optikusneuritis, für die zusätzlich als fakultativer Befund eine perioptische Gadoliniumanreicherung im Schub beschrieben wurde [75, 76]. Fundoskopisch und MR-radiologisch scheint bei MOG-IgG-positiven Patienten häufiger eine Beteiligung der Sehnervpapille vorzuliegen $[73,76]$.

\section{Weitere paraklinische Untersuchungen}

Eine weitere sinnvolle paraklinische Untersuchung ist die optische Kohärenztomografie, die in der klinischen Multiple-Sklerose-Forschung schon seit mehreren Jahren im Einsatz ist [102 - 105]. Mit ihr kann man die retinale Nervenfaserschichtdicke, die Ganglionzellschicht und mikrozystische Makulaödeme in der inneren Körnerschicht nicht invasiv erfassen $[106,107]$. Bei der multiplen Sklerose wurde eine Ausdünnung der retinalen Nervenfaserschichtdicke und der Ganglionzellschicht auch unabhängig von Schüben beschrieben. Im Gegensatz dazu scheint bei NMOSD der in der Regel erheblich ausgeprägtere strukturelle retinale Schaden im Wesentlichen oder sogar ausschließlich an klinisch manifeste Optikusneuritisschübe geknüpft zu sein $[108,109]$. 
Die Bestimmung (visuell, akustisch und magnetisch) evozierter Potenziale kann hilfreich sein, um eine (auch subklinische) Beteiligung zentraler Bahnen zu ermitteln [101, 110].

Bei Verdacht auf eine Optikusneuritis sollte immer auch eine augenärztliche Vorstellung zum Ausschluss von Differenzialdiagnosen und zur Visus- und Gesichtsfelddokumentation vor Therapie erfolgen.

\section{Differenzialdiagnosen}

\author{
Merke \\ Die häufigste und wichtigste Differenzialdiagnose \\ der NMOSD ist die multiple Sklerose.
}

Eine weitere konkurrierende Diagnose ist die ADEM (akute disseminierte Enzephalomyelitis). Sie betrifft jedoch überwiegend Kinder, tritt oft para- bzw. postinfektiös oder -vakzinal auf und manifestiert sich in Form von multifokalen und gleichzeitig das Gehirn und das Rückenmark betreffenden Demyelinisierungsherden [111]. Bei der ADEM können, insbesondere bei Kindern, (evtl. auch vorübergehend) Antikörper mit Spezifität für MOG im Serum nachgewiesen werden [111, 112].

Unter den inflammatorischen, nicht erregerbedingten Myelitiden sind vor allem die Sarkoidose [113], aber auch paraneoplastische Myelitiden (z. B. Anti-Hu, AntiCV2/CMRP5) sowie möglicherweise NMDAR-Antikörper-assoziierte Myelitiden (mit dem N-Methyl-D-Aspartat-Rezeptor-Antikörper assoziierte Myelitiden) zu berücksichtigen. Unter den erregerbedingten Myelopathien sind u. a. Tuberkulose, HTLV-1 (humanes T-lymphotropes Virus 1), HIV (humanes Immundefizienzvirus), VZV (Varizella-zoster-Virus), FSME (FrühsommerMeningoenzephalitis) und Lues zu nennen [114,115]. Zu den metabolischen Ursachen einer Myelopathie zählt vor allem der Vitamin-B12-Mangel [114]. In diesem Zusammenhang wird neben nutritiven bzw. gastritisassoziierten Ursachen [114] auch eine möglicherweise autoimmun durch AQP4-IgG vermittelte Genese (s.u.) diskutiert $[84,116]$. Ferner ist der erworbene Kupfermangel eine mögliche Ursache [117]. NMOSDassoziierte Myelonläsionen können zudem spinale Astrozytome, Lymphome oder, seltener, Glioblastome vortäuschen. Vor einer elektiven spinalen Probebiopsie müssen daher immer AQP4-IgG und MOG-IgG mittels ZBA bestimmt werden [36]. Dadurch lassen sich schwere bleibende neurologische Defizite infolge eines solchen Eingriffs vermeiden, wie sie jüngst wiederholt beschrieben wurden $[118,119]$. Vor allem im höheren Erwachsenenalter ist eine spinale Ischämie in Erwägung zu ziehen. In der kontrastmittelgestützten MRT stellt sich die ischämische Myelopathie meist erst mit einer zeitlichen Latenz von 1 - 2 Tagen und nicht kontrastmittelaffin dar.

\section{PRAXISTIPP}

Vor einer geplanten Rückenmarkbiopsie sollten aus differenzialdiagnostischen Erwägungen immer AQP4-IgG und MOG-IgG bestimmt werden. Sobald - auch bei tumorverdächtigen Läsionen AQP4-Antikörper oder MOG-IgG nachweisbar sind, muss die Indikation zur Biopsie in Rücksprache mit einem erfahrenen Zentrum interdisziplinär neu diskutiert werden. Gegebenenfalls ist zunächst ein Therapieversuch mit intravenösem Methylprednisolon (Cave: Lymphomdiagnostik!) und/oder Plasmapherese sinnvoll [118].

Bei rezidivierender, nach Ende der Steroidtherapie rasch wiederaufflammender Optikusneuritis sollte an die chronisch-inflammatorische Optikusneuritis gedacht werden. Dabei handelt es sich nach neueren Befunden um eine häufig mit MOG-IgG assoziierte Sonderform der Optikusneuritis [69, 76-78, 120, 121]. Alternativ kommen u.a. auch systemische Vaskulitiden und rheumatologische Autoimmunerkrankungen infrage [122]. Differenzialdiagnostisch sind bei Patienten mit vermuteter Optikusneuritis ferner die hereditäre Leberoptikusneuropathie sowie paraneoplastische, ischämische und erregerbedingte Optikusneuropathien zu berücksichtigen [122]. Optikusneuropathien bei NMOSD zeigen die typischen Zeichen der isolierten Optikusneuritis mit Augenbewegungsschmerz, Farbentsättigung und Schleiersehen, eine oft rasche zeitliche Dynamik im Visusabfall und häufig Skotome. Ferner sind häufiger beide Sehnerven betroffen [15, 122 124].

Merke

Prinzipiell sollten Patienten mit isolierter Optikusneuritis aufgrund der prognostischen und therapeutischen Bedeutung eines positiven Befunds immer auf AQP4-IgG und MOG-IgG untersucht werden.

Aufgrund der niedrigen Prävalenz der Erkrankung und der immer nur limitierten Spezifität diagnostischer Assays besteht jedoch wie bei jeder Screening-Untersuchung die Gefahr eines ungünstigen Verhältnisses von richtig-positiven zu falsch-positiven Ergebnissen [124]. Daher ist die Verwendung eines Assay mit hoher und in ausreichend großen Kontrollkohorten gut etablierter Spezifität unerlässlich $[67,125]$. Insbesondere bei niedrigtitrigen Befunden ist eine Bestätigung in einem 2., methodisch unabhängigen Assay oder, falls nicht verfügbar, zumindest in einer Verlaufsprobe anzustreben. 
Die multiple Sklerose kann ebenfalls mit Entzündungen des Myelons oder des N. opticus manifest werden. Um die NMOSD deshalb von der multiplen Sklerose im klinischen Alltag leichter abgrenzen zu können, wurden sog. Red Flags postuliert ( $\triangleright$ Tab. 2) [26].

Anamnestisch und im Rahmen der klinischen und laborchemischen Untersuchung sollte man zudem auf Befunde achten, die für eine begleitende Autoimmunerkrankung sprechen. Dies gilt vor allem für Kollagenosen (z. B. Arthralgien, Myalgien, Sicca-Symptome), Myasthenia gravis und Zöliakie. Sie sind nicht selten mit AQP4-IgG-positiven NMOSD vergesellschaftet [40].

\section{Pathogenese}

In ca. $80 \%$ der Fälle ist die Erkrankung Folge einer gegen AQP4 gerichteten, vornehmlich humoral vermittelten Autoimmunreaktion. Dies legen zahlreiche neuropathologische, immunologische und klinische Befunde nahe $[2,66,129-131]$ :

- NMO-Läsionen sind histopathologisch durch IgGAblagerungen sowie Astrozytenverlust charakterisiert [132-134].

- Dabei geht der Verlust von AQP4 dem Verlust von Glial fibrillary acidic Protein, d. h. dem Astrozytenuntergang, voraus; Myelin- und Axonverlust treten erst sekundär auf [135-137].

- Die Injektion von AQP4-IgG-positivem Patientenserum zusammen mit humanem Komplement in Versuchstiere verursacht Läsionen des zentralen Nervensystems, die histopathologisch die Merkmale typischer NMO-Läsionen aufweisen [138].

- Nahezu alle Patienten mit AQP4-IgG haben eine NMO(-SD).

- Akuten NMO-Schüben geht ein Anstieg der AQP4IgG-Serumtiter und der AQP4-IgG-produzierenden Plasmablasten im Blut voraus. Die klinische Remission ist von einem Titerabfall begleitet $[68,130,139$ 141].

- B-Zell-depletierende Therapien (z. B. Rituximab [82, 142 - 144]) führen sowohl zu einer Senkung der AQP4-IgG-Titer als auch zu klinischer Stabilisierung. Ein Wiederanstieg der AQP4-IgG-Titer am Ende des Therapiezyklus ist mit einem unmittelbaren Rezidivrisiko verbunden $[130,144]$. Auch die Unterbindung der B-Zell-Reifung durch Blockade des IL-6Rezeptors (Tocilizumab [145-149]) und IgG-depletierende Verfahren (Plasmapherese, Immunabsorption [150 - 154]) sind effektive Therapiemöglichkeiten.

- Die Expression von AQP4 ist in den Sehnerven und im Myelon besonders hoch und findet sich dort in supramolekularen AQP4-Aggregaten, die eine verstärkte Bindung von AQP4-IgG bewirken [155]. Dies korreliert gut mit den Prädilektionsorten der AQP4IgG-positiven NMO.
- Tab.2 Befunde, die eher gegen NMOSD sprechen (sog. Red Flags) [26].

\begin{tabular}{|c|c|}
\hline Kategorie & Details \\
\hline $\begin{array}{l}\text { klinische } \\
\text { Symptome und } \\
\text { Liquorbefunde }\end{array}$ & $\begin{array}{l}\text { - zwischen den akuten Attacken stattfindende } \\
\text { Krankheitsprogression (suggestiv für multiple } \\
\text { Sklerose) } \\
\text { - Zeitintervall von < } 4 \text { h oder > } 4 \text { Wochen bis zur } \\
\text { maximalen Ausprägung der Symptome (z. B. } \\
\text { suggestiv für spinale Ischämie bzw. Myelon- } \\
\text { beteiligung bei Sarkoidose oder spinalem } \\
\text { Tumor) } \\
\text { - oligoklonale Banden auch außerhalb eines } \\
\text { akuten Schubes: } 95 \% \text { bei multipler Sklerose } \\
\text { versus } 8 \% \text { bei AQP4-IgG-positiver NMOSD [60] } \\
\text { - positive MRZ-Reaktion (suggestiv für multiple } \\
\text { Sklerose) [86, 87,126] }\end{array}$ \\
\hline $\begin{array}{l}\text { Komorbiditäten, } \\
\text { die NMOSD } \\
\text { imitieren können }\end{array}$ & $\begin{array}{l}\text { - Sarkoidose (suggestiv: mediastinale Lymph- } \\
\text { adenopathien, Fieber, Nachtschweiß, erhöhte } \\
\text { Serumkonzentrationen von ACE oder löslichem } \\
\text { sIL-2R [119, 127] } \\
\text { - Neoplasien oder Paraneoplasien (z. B. } \\
\text { Lymphome, CV2/CRMP5-Antikörper- oder } \\
\text { Hu-Antikörper-assoziierte Optikusneuropathie } \\
\text { und Myelopathie [128], Ma-Antikörper- } \\
\text { assoziierte Dienzephalitis) } \\
\text { - chronische Infektionen (z. B. HIV-Myelopathie, } \\
\text { Syphilis, VZV-Reaktivierung) }\end{array}$ \\
\hline \multirow[t]{2}{*}{$\begin{array}{l}\text { radiologische } \\
\text { Befunde }\end{array}$} & $\begin{array}{l}\text { kraniale MRT: } \\
\text { - multiple-Sklerose-typische Läsionen (in T2w } \\
\text { bzw. FLAIR-Sequenzen hyperintens im Marklager, } \\
\text { perpendikulär zu den Seitenventrikeln ausgerich- } \\
\text { tet [Dawson-Finger], angrenzend an den Seiten- } \\
\text { ventrikel im unteren Temporallappen, juxta- } \\
\text { kortikal, kortikal) } \\
\text { - multiple-Sklerose- und NMOSD-atypische } \\
\text { Läsionen (z. B. über >3 Monate anhaltende } \\
\text { Kontrastmittelanreicherung) }\end{array}$ \\
\hline & $\begin{array}{l}\text { spinale MRT: } \\
\text { - Läsionen mit einer Längsausdehnung über } \\
\text { <3 vertebrale Segmente in sagittalen T2w } \\
\text { Sequenzen (suggestiv für multiple Sklerose; } \\
\text { kurzstreckige Läsionen aber selten auch bei } \\
\text { AQP4-IgG möglich: } 10 \text { - } 15 \% \text { mindestens einmal } \\
\text { im Krankheitsverlauf [1]) } \\
\text { - vorwiegend (>70\%) peripher im Myelon lokali- } \\
\text { sierte Läsionen in axialen T2w Sequenzen } \\
\text { - diffuse, unscharf abgegrenzte Signalsteigerung } \\
\text { in T2w Sequenzen (oft bei lange bestehender } \\
\text { oder bei progressiver multipler Sklerose) }\end{array}$ \\
\hline \multicolumn{2}{|c|}{$\begin{array}{l}\text { ACE = angiotensinkonvertierendes Enzym; AQP4-IgG = Aquaporin-4-Immunglobulin } \\
\text { G; FLAIR = Fluid-attenuated Inversion-Recovery; HIV = humanes Immundefizienz- } \\
\text { virus; sIL-2 R = Interleukin-2-Rezeptor; MRZ-Reaktion = Masern-Röteln-Zoster-Anti- } \\
\text { körper-Reaktion; NMOSD = Neuromyelitis optica Spectrum Disorders; VZV=Vari- } \\
\text { zella-zoster-Virus }\end{array}$} \\
\hline
\end{tabular}

Die AQP4-IgG-vermittelte komplementabhängige Zytotoxizität gilt als wesentlicher Schädigungsmechanismus [18,156-158]. So gehören AQP4-IgG mehrheitlich zur komplementaktivierenden IgG1-Subklasse $[156,157]$. Darüber hinaus finden sich in NMO-Läsionen C9neo-Ablagerungen als Zeichen einer Aktivierung des Komplementsystems $[134,136,159]$ und im Liquor 
ein erhöhter C5a-Spiegel [160]. Der Komplementinhibitor Eculizumab ist in der Lage, die Schubrate signifikant zu reduzieren $[161,162]$. Daneben sind jedoch auch zahlreiche Immunzellen an der Pathogenese der NMO beteiligt. So sind in NMO-Läsionen [159] und/ oder im Liquor im akuten Schub B-Zellen, T-Zellen, neutrophile und eosinophile Granulozyten und Makrophagen nachweisbar $[3,14,60]$. Proinflammatorische Zytokine (IL-6, BAFF [B-Zell-aktivierender Faktor], APRIL [proliferationsinduzierender Ligand], CXCL13 [CX-C-Motiv-Ligand 13]) schaffen ein B-Zell-freundliches Milieu. Immunregulatorische Elemente wie IL-10 oder regulatorische $\mathrm{B}$-Zellen werden hingegen supprimiert [163 - 167]. Die Rolle weiterer Botenstoffe des zentralen Nervensystems sowie von freigesetztem Glutamat und dadurch entstehender glutamatvermittelter Übererregbarkeit wird kontrovers diskutiert [2, 168-170]. Der Umstand, dass auch einige AQP4-IgG-seronegative Patienten auf antikörperdepletierende Therapien ansprechen, legt nahe, dass in diesen Fällen andere Autoantikörper eine Rolle spielen könnten (MOG-lgG, NMDAR-IgG, Antikörper unbekannter Spezifität [171]). Die Rolle weiterer zellulärer Elemente des Immunsystems in der Pathogenese der NMO wie z. B. von T-Zellen oder neutrophilen Granulozyten usw. ist aktuell Gegenstand der Forschung $[172,173]$. Das bisweilen fehlende Ansprechen auf B-Zell-depletierende Therapien ist evtl. durch langlebige AQP4-spezifische, autoreaktive Plasmazellen in Knochenmarksnischen erklärbar, die von gegen CD20 gerichteten Therapien nicht erreicht werden. So wurde es für den SLE bereits gezeigt [174].

Eine ausführlichere Darstellung der Pathogenese der AQP4-lgG-positiven NMO findet sich in der Literatur $[2,66,130]$.

\section{Therapie}

Die NMOSD ist eine chronische und meist schubförmig verlaufende Erkrankung. Die Therapie basiert auf 3 Säulen:

- Behandlung akuter Schübe mit Glukokortikosteroiden und/oder Aphereseverfahren

- Rezidivprophylaxe mittels einer immunsuppressiven Langzeittherapie

- Verbesserung der Residualsymptome (Schmerz, Spastik, Blasenstörungen, sensible Ataxie) durch symptomatische Therapie und rehabilitative Maßnahmen

\section{Merke}

Von entscheidender Bedeutung ist es, akute Schübe der NMOSD rasch und konsequent (evtl. eskalierend) zu behandeln und weitere Schübe zu verhindern.
Die krankheitsbedingte Behinderung nimmt bei Patienten mit NMOSD, anders als bei Patienten mit multipler Sklerose, fast ausschließlich durch die Schübe bedingt weiter zu. Die Remissionstendenz unbehandelter Schübe ist oft schlecht und das Mortalitätsrisiko ist vor allem hoch, wenn die Schübe hohe zervikale Regionen und den Hirnstamm betreffen [1,175-177]. Derzeit fehlen kontrollierte Studien zur Behandlung der NMOSD. Alle Empfehlungen beruhen daher auf retrospektiven Auswertungen sowie auf Expertenempfehlungen $[1,178,179]$.

\section{Therapie akuter Schübe}

\section{Methylprednisolon}

Für die Therapie akuter NMOSD-Attacken stehen mehrere Optionen bzw. ein Eskalationsschema zur Verfügung $[1,175,176]$. Ähnlich wie bei der multiplen Sklerose wird zunächst nach klinischem und paraklinischem Ausschluss eines Infekts Methylprednisolon intravenös in einer Dosierung von $1000 \mathrm{mg} /$ Tag über einen Zeitraum von 3-5 Tagen unter Magenschutz (vorzugsweise mit Protonenpumpeninhibitor) und Thromboseprophylaxe verabreicht. Letztere ist bei immobilisierten Patienten, Ultrahochdosistherapie und erhöhtem Thromboserisiko obligat. In einer größeren japanischen Fallserie sprachen die schubassoziierten Symptome bei NMOSD allerdings weniger gut auf Methylprednisolon an als bei multipler Sklerose [180]. Fakultativ kann die Steroidtherapie oral ausgeschlichen werden [181].

\section{Plasmapherese}

Da eine initiale Schubtherapie mit Kortikosteroiden viele NMOSD-Attacken nur unzureichend beeinflusst, ist bei einer unvollständigen Remission nach dem ersten Therapiezyklus eine Therapieeskalation mit antikörpereliminierenden Aphereseverfahren indiziert (Plasmapherese, Immunadsorption) [1,182]. Gemäß einer retrospektiven Arbeit kann eine Kombinationstherapie mit Kortikosteroiden und Plasmapherese (nacheinander verabreicht) im Schub den Wert auf der EDSS (Expanded Disability Status Scale) wirkungsvoller verbessern als intravenöse Kortikosteroide alleine [183]. Zur Plasmapherese werden meist 5-7 Zyklen mit Plasmaaustausch an jedem 2.Tag durchgeführt, je nach Schweregrad und Ansprechen der Symptome auch mehr [1]. Davon profitieren sowohl AQP4-IgG-seropositive als auch AQP4-lgG-seronegative Patienten [184, 185]. Bei bekanntem fehlendem Ansprechen auf Methylprednisolon kann auch direkt eine Plasmapherese zur Therapie eines schwereren Schubes initiiert werden, vor allem bei isolierten Myelitisschüben [185]. Dieses Vorgehen ist vor allem bei rekurrierender Myelitis vorteilhaft und könnte einer Pulstherapie mit Methylprednisolon überlegen sein [185]. 


\section{Immunadsorption}

Die Datenlage zur Immunadsorption ist begrenzt. Eine der Plasmapherese vergleichbare Wirksamkeit gilt allerdings als wahrscheinlich [185]. Eine Immunadsorption bietet sich insbesondere an, wenn eine Plasmapherese aufgrund von Kontraindikationen nicht durchgeführt werden kann, z. B. bei einer bekannten Allergie gegen Fremdeiweiß sowie möglicherweise in der Schwangerschaft (s.u.). Bei guter Verträglichkeit kann auch eine Methylprednisolon-Pulstherapie in eskalierender Dosis (täglich $2000 \mathrm{mg}$ intravenös über weitere 5 Tage) in Betracht kommen. Sie scheint allerdings hinsichtlich Verträglichkeit und Effektivität der Therapieeskalation mittels Plasmapherese unterlegen zu sein [185].

\section{Rezidivprophylaxe}

In Anbetracht der als gesichert geltenden Autoimmunpathogenese der NMOSD kommen verschiedene Immunsuppressiva zum Einsatz. Aufgrund der Seltenheit der NMOSD fehlen jedoch kontrollierte prospektive Studien, sodass gegenwärtig alle Wirkstoffe „off Label“ eingesetzt werden. Dabei werden vor allem Azathioprin (bei moderatem Verlauf), in der Wirklatenzphase (3-6 Monate) meist in Kombination mit oralen Steroiden, und Rituximab als Substanzen der ersten Wahl verwendet $[1,179]$. Wie für immunsupprimierte Patienten allgemein üblich, sollten die aktuellen Leitlinien der STIKO (der ständigen Impfkommission des RobertKoch-Instituts) berücksichtigt werden.

INFO

Unbedingt zu beachten ist, dass einige MultipleSklerose-Therapeutika wie Interferon- $\beta$ [145], Natalizumab [186-188], Glatiramerazetat [189], Fingolimod [190] und mutmaßlich auch Alemtuzumab $[148,191]$ bei NMOSD-Patienten vermutlich wirkungslos sind oder den Krankheitsverlauf sogar wesentlich verschlechtern können. So können sie die Schubfrequenz erhöhen und zum Teil fulminante Schübe auslösen [35, 186, 190, 192 195]. Ähnliches könnte auch für MOG-IgG-assoziierte Fälle gelten [76].

\section{Azathioprin}

Durch unspezifische Effekte unterdrückt Azathioprin als Purinantimetabolit die Regeneration von Lymphozyten. Dadurch ergibt sich ein robuster immunsuppressiver Effekt, wenn Azathioprin in einer Dosierung von etwa $2-3 \mathrm{mg} / \mathrm{kg}$ Körpergewicht verwendet wird. In einer retrospektiven Auswertung größerer Kohorten konnte Azathioprin die Schubraten um 72 bzw. 66 \% reduzieren und die neurologischen Behinderungen bei zahlreichen Patienten stabilisieren $[196,197]$. Dabei ergab eine retrospektive Studie, dass eine körpergewichtsadaptierte Dosierung von mindestens $2 \mathrm{mg} / \mathrm{kg}$ Körpergewicht der in Deutschland oft standardmäßig verordneten Tagesdosis von $150 \mathrm{mg}$ therapeutisch überlegen sein könnte [197].

Das Nebenwirkungsspektrum der Substanz ist vor allem durch Blutbildveränderungen und Leberwerterhöhungen charakterisiert. Die optimale therapeutische Wirksamkeit wird durch Lymphozytenwerte zwischen 600 und 1000/ $\mu$ l und eine Erhöhung des Erythrozytenvolumens um $5 \%$ angezeigt $[1,53,197]$. Da die Wirkung von Azathioprin sich erst nach etwa 3-6 Monaten entfaltet und in diesem Zeitraum das Rezidivrisiko möglicherweise erhöht ist, muss überlappend mit oralen Kortikosteroiden (z. B. Prednisolon) behandelt werden. Vor Therapiebeginn kann die Aktivität der Thiopurinmethyltransferase bestimmt werden, da bei genetisch bedingter verringerter Enzymaktivität mit einer schlechteren Verträglichkeit und dem Risiko einer Agranulozytose zu rechnen ist [1].

Merke

Bei langjähriger Anwendung von Azathioprin sowie hoher Intensität der Immunsuppression steigt das Risiko für Non-Hodgkin-Lymphome und andere Malignome, insbesondere Karzinome der Haut. Es sollte daher auf einen guten Sonnenschutz geachtet werden.

\section{Rituximab}

Die Therapie der NMO und NMOSD mit dem monoklonalen CD20-Antikörper Rituximab gilt gemäß retrospektiver Studien als relativ gut verträglich und reduziert die Schubraten in 87,0 - 96,3\% der Fälle bzw. führt in 44,0-77,0\% der Fälle zu anhaltender Schubfreiheit. Rituximab gilt als eines der am besten zur Rezidivprophylaxe der NMOSD geeigneten Immunsuppressiva. Prospektive Vergleichsstudien fehlen jedoch bislang [143, 198 - 200]. Die Wirkung beruht auf einer Verminderung der im Blut zirkulierenden CD20-positiven BZellen bis unter die Nachweisgrenze.

\footnotetext{
Cave

Das Hauptrisiko bei Verwendung dieses chimären Antikörpers besteht in allergischen Reaktionen auf Fremdeiweiß sowie in Infektionen.
}

Die verwendeten Schemata orientieren sich an rheumatologischen Behandlungskonzepten. Am häufigsten kommt die intravenöse Gabe von jeweils 1000 mg Rituximab an den Tagen 1 und 15 zum Einsatz, gefolgt von halbjährlichen Infusionen von je 1 oder $2 \times 1000 \mathrm{mg}$. Alternativ können initial $375 \mathrm{mg} / \mathrm{m}^{2}$ Körperoberfläche einmal pro Woche in 4 aufeinanderfolgenden Wochen verabreicht werden. Diese festen Dosierungsschemata bergen das Risiko, dass vor Ablauf von 6 Monaten 
wieder B-Zellen im Blut nachweisbar sind. Daneben gibt es die Möglichkeit eines engmaschigen B-Zell-Monitoring mit Redosierung im Fall einer Rekonstitution von CD19+- oder CD20+-B-Zellen bzw. CD27 +-Memory-B-Zellen [179]. Zur maximalen Therapiedauer gibt es derzeit keine klaren Empfehlungen; kumulative Effekte sind nicht bekannt. Bislang ist unklar, ob bei langfristiger Behandlung eine reduzierte Dosis zur suffizienten Suppression der Krankheitsaktivität ausreicht. Darüber hinaus ist zu beachten, dass in den ersten Wochen nach dem initialen Therapiezyklus Schübe vorkommen können, mutmaßlich infolge einer vorübergehenden Erhöhung der Konzentration proinflammatorischer Zytokine wie IL-6, BAFF und TNF- $\alpha$ (Tumornekrosefaktor $\alpha$ ) $[201,202]$.

Vor Beginn einer Rituximab-Therapie müssen mehrere Aspekte beachtet werden:

- Das immunologische Gedächtnis wird zu dem Zeitpunkt der ersten Rituximab-Infusion „eingefroren“. Daher sollte der Impfstatus für Totimpfstoffe (gemäß den geltenden Leitlinien der STIKO) unbedingt und mit ausreichender Vorlaufzeit (möglichst 2 Wochen) überprüft und nach Bedarf aufgefrischt werden.

- Eine Reaktivierung von latenten Infektionen ist möglich. Zum Ausschluss einer Tuberkulose sollte mindestens ein Röntgenthorax, möglichst aber ein Quantiferon-Test durchgeführt werden. Sollte dieser positiv ausfallen, ist zu überlegen, ob eine alternative Therapie eingeleitet werden kann oder eine Prophylaxe für die Dauer der Rituximab-Therapie durchgeführt werden muss. Außerdem sollten eine Hepatitisserologie und ggf. auch ein HIV-Test veranlasst werden.

- Unter Therapie mit Rituximab sind Fälle von PML (progressiver multifokaler Leukenzephalopathie) aufgetreten, wenngleich dies bisher keine NMOSDPatienten betraf. Über dieses PML-Risiko müssen die Patienten mit der Möglichkeit zu ausreichender Bedenkzeit aufgeklärt werden.

Offenbar besteht zudem das Risiko einer Hypogammaglobulinämie, die im Zusammenspiel mit der Rituximab-induzierten Leukopenie für infektiöse Komplikationen prädisponierend sein könnte [203]. Vor den jeweiligen Rituximab-Infusionen sollten die Patienten klinisch-neurologisch untersucht und es sollte ein Infekt ausgeschlossen werden. Danach kann nach Prämedikation (1000 mg Paracetamol, $100 \mathrm{mg}$ Prednisolon, $4 \mathrm{mg}$ Dimetindenmaleat intravenös) mit der Infusion unter Beachtung einer langsamen Tropfgeschwindigkeit begonnen werden.

\section{Mycophenolatmofetil}

Mycophenolatmofetil konnte die Schubraten im Vergleich zum Zeitpunkt vor Behandlungsbeginn deutlich reduzieren (um 74-88\%) [198-200,204,205]. Die orale Tagesdosis, verteilt auf 2 Gaben, betrug in den bisher verfügbaren Studien im Mittel $2000 \mathrm{mg}$ (gewichtsadaptiert, variierend von $750-3000 \mathrm{mg}$ ). Die Lymphozytenwerte sollten auf 1000 - $1500 / \mu$ abfallen. Die Wirklatenz kann bis zu 3 Monaten betragen, sodass in der Zwischenzeit eine Therapie mit oralen Kortikosteroiden sinnvoll scheint [198]. Bei NMOSD-Patienten ist unter Mycophenolatmofetil-Therapie bisher kein PML-Fall aufgetreten, wohl aber in der Indikation nach Organtransplantation [206]. Nebenwirkungen, die im Rahmen der NMOSD-Therapie berichtet wurden, waren u. a. eine erhöhte Fotosensibilität der Haut, Exantheme sowie eine erhöhte Infektanfälligkeit.

\section{Interleukin-6-Rezeptor-Blockade}

Der humanisierte monoklonale Antikörper Tocilizumab ist ein IL-6R-Antagonist (ein Antagonist des Interleukin-6-Rezeptors) ohne aktivierende Eigenschaften und wirkt pleiotrop antiinflammatorisch. Tocilizumab hemmt u.a. die Differenzierung von B-Zellen in antikörpersezernierende Plasmazellen und das Überleben der Plasmazellen. Dies ist relevant, da bei NMOSD Plasmablasten sowohl im Blut als auch im Liquor numerisch erhöht sind, IL-6 in erhöhten Konzentrationen messbar ist und Hinweise auf eine Stimulation zur IL-6Produktion durch AQP4-IgG bestehen $[140,167,207]$. Tocilizumab wurde als relativ sichere und wirksame Therapieoption für anderweitig therapierefraktäre Patienten beschrieben [145-149].

\section{Intravenöse Immunglobuline}

Intravenöse Immunglobuline werden erfolgreich zur Behandlung verschiedener neuroimmunologischer Erkrankungen eingesetzt, u.a. bei Guillain-Barré-Syndrom und in der myasthenen Krise. Die pleiotropen Effekte umfassen u.a. die Neutralisation von Autoantikörpern, die Blockade von Fcy-Rezeptoren und Immunzellaktivierung und die Komplementinhibition [47]. Bislang gibt es nur sehr kleine Fallserien zu NMOSD, in denen die Anzahl der Schubraten unter Therapie mit intravenösen Immunglobulinen verringert wurde [1, 179,208]. In Einzelfällen wurde intravenöses Immunglobulin auch zur Behandlung akuter NMOSD-Attacken erfolgreich eingesetzt [209].

\section{Mitoxantron}

Trotz relevanter Nebenwirkungen (insbesondere Kardiotoxizität [210,211] und erhöhtem Leukämie- [212] und Darmkrebsrisiko [213]) ist Mitoxantron eine mögliche Therapiealternative zu den vorgenannten Immunsuppressiva. Mitoxantron hemmt die Topoisomerase II, stört die Regeneration von Lymphozyten und Makrophagen und inhibiert dadurch die B-Zell-Aktivierung 
[214]. In mehreren Fallserien wurde eine deutliche Reduktion um 75 bzw. $80 \%$ der jährlichen Schubrate und bei einem Teil der Patienten sogar Schubfreiheit beobachtet [182, 215-217].

\section{Methotrexat}

Zur Wirksamkeit des Folsäureantagonisten Methotrexat liegen 3 kleine Fallserien vor, in denen die Schubraten um 64 bzw. 87\% reduziert waren, zum Teil unter Kombinationstherapie mit weiteren Immunsuppressiva. Bei einem Teil der Patienten kamen gar keine Schübe mehr vor [218-220].

\section{Ciclosporin A und Tacrolimus}

Zu diesen beiden Kalzineurininhibitoren gibt es ebenfalls nur Daten aus kleinen Fallserien. Die Wirkstoffe wurden oft zusammen mit Prednisolon verabreicht und erzielten bei einem Teil der Patienten Schubfreiheit und eine Stabilisierung des Behinderungsgrads, gemessen am EDSS-Score [221, 222].

\section{Cyclophosphamid}

Dieses Alkylans ist außer für die Therapie von Leukämien und Lymphomen auch zur Behandlung einiger Autoimmunerkrankungen zugelassen, darunter SLE und Vaskulitiden. Es zeigte in 3 kleinen Fallserien mit 4, 5 und 7 Patienten keinen signifikanten Effekt bzw. sogar eine Verschlechterung bei einigen Behandelten, sodass Cyclophosphamid bislang nicht allgemein empfohlen werden kann [182, 200, 223].

\section{Ausblick auf neue Therapiemöglichkeiten}

In klinischen Studien befinden sich aktuell u. a. B-Zelldepletierende monoklonale Antikörper gegen CD19 [224] sowie gegen den Komplementfaktor C5a [161, 162] und kompetitive, nicht pathogene AQP4-spezifische Antikörper [225]. Zur Behandlung von Schüben werden im Rahmen von klinischen Studien u. a. der Angiogenesehemmer Bevacizumab [226] und C1-Esterase-Inhbitoren eingesetzt [227]. Ein Überblick dazu findet sich in der Literatur [182].

\footnotetext{
Merke

Die Therapie der NMOSD muss nach aktuellen Kenntnissen immunsuppressiv erfolgen. Viele der gängigen Multiple-Sklerose-Medikamente sind unbedingt zu vermeiden.
}

\section{Sondersituationen}

\section{Schwangerschaftswunsch und Schwangerschaft}

Eine Schwangerschaft ist bei NMOSD-Patientinnen nicht grundsätzlich kontraindiziert. Trotz zunehmender Erfahrung zur Basis- und Schubtherapie ist die Datenlage zum aktuellen Zeitpunkt jedoch weiterhin be- grenzt. Ergebnisse retrospektiver Studien weisen auf eine möglicherweise leicht erhöhte Schubrate in der Schwangerschaft hin $[228,229]$; evtl. ist der Triggermechanismus ein erhöhtes Antigenangebot bei plazentar reichlich exprimiertem AQP4 [230]. Darüber hinaus besteht wohl ein erhöhtes Risiko für Fehlgeburten und Präeklampsie [231]. Aus Einzelfallberichten [230] und tierexperimentellen Studien gibt es Hinweise auf eine entzündliche Schädigung auch der Plazenta durch AQP4-IgG [232, 233].

\section{Merke}

Einige Autoren schließen daraus, dass eine Schwangerschaft vertretbar sei, die Patientinnen jedoch engmaschig überwacht werden müssten [231, 234].

Vor Konzeption sollte man klären, ob isoliert oder im Rahmen eines konkomitanten SLE gleichzeitig ein Antiphospholipidsyndrom besteht. In diesem Fall werden eine spezialisierte rheumatologische Mitbetreuung sowie ggf. die präventive Gabe von Heparin (möglichst niedermolekular aufgrund des Sicherheitsprofils [235]) während der gesamten Schwangerschaft zur Vermeidung venöser Thrombosen sowie von niedrigdosierter Azetylsalizylsäure zur Prophylaxe arterieller Embolien empfohlen [236, 237].

Eine nützliche Quelle neben den jeweiligen Fachinformationen zur möglichen Therapieumstellung vor einer geplanten Schwangerschaft findet sich auf der von der Charité-Universitätsmedizin Berlin unterhaltenen Internetseite zur Embryotoxizität verschiedenster Substanzen [238]. Dort sind unter Berücksichtigung des zu diesem Thema eingeschränkten Kenntnisstands krankheitsübergreifend Empfehlungen zu Immunsuppressiva und Schwangerschaft aufgeführt:

- Azathioprin hat während der Schwangerschaft ein eher günstiges Risikoprofil.

- Mycophenolatmofetil ist während der Konzeption und Schwangerschaft kontraindiziert; es liegt ein Rote-Hand-Brief bezüglich schwerwiegender Teratogenität vor, der eine sichere Verhütung für Frauen und Männer erfordert.

- Für Rituximab wird bei Kinderwunsch eine Umstellung empfohlen, sofern medizinisch vertretbar. Dabei berichten 2 Einzelfallberichte einen günstigen Schwangerschaftsverlauf für Mutter und Kind nach versehentlicher Rituximab-Gabe [239, 240].

- Eine Therapie mit Prednisolon birgt ein erhöhtes Risiko für Lippen-Kiefer-Gaumen-Spalten beim Kind und für die Entwicklung einer diabetogenen Stoffwechsellage, für Thrombosen und für psychiatrische Nebenwirkungen bei der Mutter. Die Erhaltungsdosis zwischen Woche 8 und 11 sollte möglichst $10 \mathrm{mg} /$ Tag nicht überschreiten. Das dürfte jedoch bei hoher NMOSD-Krankheitsaktivität keinen ausreichenden Schutz erbringen. 
Kommt es während der Schwangerschaft zu einem akuten Schub, ist als Alternative zur Plasmapherese eine Behandlung mittels Immunadsorption zu erwägen. Denn diese erfordert im Vergleich zur Plasmapherese keinen Ersatz des Plasmas durch Fremdpräparate (z. B. Humanalbumin oder Fresh frozen Plasma). Dadurch wird auch das Risiko einer allergischen Reaktion reduziert. Darüber hinaus hat dieses Verfahren einen geringeren Einfluss auf die Blutgerinnung. Die möglichen Nebenwirkungen einer Methylprednisolon-Stoßtherapie (s.o.) rechtfertigen womöglich einen ersten Therapieversuch mittels Immunadsorption. Einschränkend gilt jedoch, dass bislang nur wenige Ergebnisse zum therapeutischen Nutzen der Immunadsorption bei NMOSD publiziert wurden.

\section{Ältere Patienten}

Nach Befunden aus 2 Fallserien zur Erstmanifestation von NMOSD im Senium sind Schübe im höheren Lebensalter häufig schwer und gehen mit einer höheren Behinderungsrate und schubassoziierter Morbidität einher [36, 241].

Merke

Im Umgang mit älteren NMOSD-Patienten sind Komorbiditäten und Begleittherapien zu beachten, die ggf. die Akuttherapie oder die Rezidivprophylaxe im Hinblick auf Nebenwirkungen verkomplizieren.

\section{Pädiatrische Manifestationen von Neuromyelitis optica Spectrum Disorders}

Bezüglich der Besonderheiten der pädiatrischen NMOSD wird auf Übersichtsartikel verwiesen [26, 242]. Zusammengefasst wird davon ausgegangen, dass es sich prinzipiell um dieselbe Erkrankung mit einer etwas abweichenden klinischen Präsentation handelt. So wurden bislang etwas häufiger monophasische Krankheitsverläufe beobachtet (bei zum Teil jedoch relativ kurzer Nachbeobachtungszeit) und klinisch manifeste Hirnläsionen beschrieben. Eine Herausforderung ist die Abgrenzung zur ADEM. Im Gegensatz zur ADEM, die oft mit MOG-IgG assoziiert ist, können allerdings auch bei der pädiatrischen NMOSD meist AQP4-Antikörper nachgewiesen werden.

\section{Merke}

Auch bei pädiatrischer NMOSD ist die Bestimmung von AQP4-IgG stets angezeigt.

\section{Komorbiditäten}

AQP4-IgG-seropositive NMOSD treten nicht selten in Verbindung mit anderen systemischen oder organspezifischen Autoimmunerkrankungen auf $[3,6,17]$. Autoimmune Komorbiditäten sind insbesondere
- SLE [40, 243, 244],

- Sjögren-Syndrom [40, 243-247],

- Myasthenia gravis [38, 39],

- seltener auch Zöliakie [248, 249],

- autoimmun vermittelte Vitamin-B12-Defizienz [84, 116] und

- Schilddrüsenerkrankungen [3].

Läsionen des zentralen Nervensystems bei AQP4-IgGseropositiven Patienten mit begleitenden systemischen Autoimmunerkrankungen wie SLE und SjögrenSyndrom werden heute in aller Regel als AQP4-IgG-vermittelte Schädigung interpretiert. Ein eigenständiger Beitrag der Kollagenose (z. B. vaskulitisch) ist im Einzelfall jedoch möglich $[40,124,243,244,250]$. Der Umstand, dass die AQP4-IgG-positiven NMOSD meist ohne begleitende Kollagenose auftreten, legt nahe, dass es sich um eigenständige, aber auf Grundlage einer ausgeprägten autoimmunen Prädisposition gelegentlich zusammen vorliegende Entitäten handelt. Die Immunsuppression bei solchen Überlappungssyndromen kann ggf. beide Entitäten wirksam beeinflussen, wie z. B. für die IL-6R-Blockade mit Tocilizumab berichtet [251]. In solchen Fällen ist eine enge Zusammenarbeit zwischen internistisch-rheumatologischen und neurologischen Abteilungen angezeigt.

\section{Myelin-Oligodendrozyten-Glykoprotein- Enzephalomyelitis}

Trotz sensitiver Testmethoden bleiben etwa $20 \%$ der Patienten mit NMOSD-Phänotyp auch dann noch AQP4-IgG-seronegativ, wenn die Tests wiederholt werden. Die genauere Charakterisierung einer Untergruppe von Patienten, die Antikörper gegen MOG aufweisen und sich mit Myelitis, Optikusneuritis oder auch einem ADEM-ähnlichen Bild (vor allem pädiatrische Patienten) vorstellen, ist Gegenstand der aktuellen Forschung $[71,72,75,252,253]$. Die MOG-Enzephalomyelitis ist eine immunpathophysiologisch klar von der AQP4-IgG-positiven NMO abgrenzbare Entität [70, 74]. Die Immunreaktion ist gegen ein oligodendrozytäres Protein gerichtet, sodass es sich um eine primär demyelinisierende Erkrankung handelt. Wie AQP4-IgG wird auch MOG-IgG vornehmlich außerhalb des zentralen Nervensystems gebildet und kann daher besser im Serum als im Liquor nachgewiesen werden [69]. In der Behandlung der MOG-Antikörper-vermittelten Erkrankung ist aktuell nicht eindeutig geklärt, welche Patienten einer immunsuppressiven Basistherapie bedürfen. In der Vergangenheit wurden auf Grundlage kleinerer Fallserien mit kurzer Nachbeobachtungszeit eine spontane Schubremission sowie ein insgesamt günstiger Krankheitsverlauf auch ohne immunsuppressive Therapie postuliert. Neuere Studien bestätigen dies jedoch nicht: Auch die MOG-lgG-assoziierte Optikusneuritis und Myelitis nimmt - zumindest bei Erwachsenen mehrheitlich einen rezidivierenden Verlauf und kann 
unbehandelt zu schwerer Behinderung bis hin zu Erblindung und Gehbehinderung führen [69, 76-78,254 $-256]$.

\section{Merke}

Eine immunsuppressive Dauertherapie sollte daher auch bei MOG-IgG-positiven Patienten immer erwogen werden.

In Deutschland beschäftigt sich die Neuromyelitis-optica-Studiengruppe, die auch ein Patientenregister unterhält, seit vielen Jahren wissenschaftlich mit Fragen der Autoimmunpathogenese, Epidemiologie, Diagnostik und Therapie der NMO. Einen Überblick über die beteiligten Studienzentren findet sich auf der Homepage der Studiengruppe $[1,178,257]$.

\section{Fazit}

Vor 20 Jahren war die NMO noch durch rasche Progredienz und eine hohe Sterblichkeit gekennzeichnet (5Jahres-Überlebensrate: $68 \%$ bei schubförmigem Verlauf). Heute sind Todesfälle selten geworden. Der Langzeitverlauf lässt sich durch eine frühe und langfristige immunsuppressive Behandlung sowie durch eine konsequente, frühe und ggf. eskalierende Therapie akuter Schübe (einschließlich Plasmapherese) deutlich verbessern. Die NMOSD wird somit zunehmend zu einer behandelbaren chronischen Erkrankung. Dennoch birgt ihre Behandlung weiterhin enorme (auch interdisziplinäre) Herausforderungen, die weitere Studien erfordern. So liegen bislang aufgrund der niedrigen Prävalenz der Erkrankung keine großen, randomisierten kontrollierten Therapiestudien vor. Auch fehlen Daten zur Behandlung in Sondersituationen wie bei Überlappungssyndromen oder in der Schwangerschaft und zur Therapieeskalation bei schweren therapierefraktären Verläufen weitgehend. Die Entdeckung von AQP4-IgG hat es ermöglicht, die NMO meist sicher von der multiplen Sklerose abzugrenzen. Dies ist von entscheidender therapeutischer Bedeutung, weil einige Medikamente, die erfolgreich zur Behandlung der multiplen Sklerose eingesetzt werden (z. B. Interferon- $\beta$, Natalizumab), den Verlauf der AQP4-IgG-positiven NMOSD wesentlich verschlechtern können. Neue internationale Konsensuskriterien und sog. Red Flags helfen bei der Abgrenzung AQP4-IgG-negativer Patienten mit NMO von der konventionellen multiplen Sklerose. Der Nachweis von AQP4-lgG sollte mittels zellbasierter Assays erfolgen. Bei AQP4-IgG-seronegativen Patienten ist eine Wiederholung des Tests zu einem späteren Zeitpunkt ratsam; ferner wird eine Testung auf MOG-IgG empfohlen.

\section{KERNAUSSAGEN}

- Die NMO ist eine autoimmun vermittelte entzündliche Erkrankung des zentralen Nervensystems, die insbesondere das Rückenmark und die Sehnerven betrifft. Neuropathologisch ist die NMO durch Antikörper- und Komplementablagerungen, Astrozytenverlust, nekrotische Veränderungen mit Infiltration neutrophiler und eosinophiler Granulozyten und sekundären Untergang von Oligodendrozyten und Neuronen gekennzeichnet.

- Bei der Abgrenzung gegenüber der klinisch ähnlichen, aber deutlich häufigeren multiplen Sklerose hilft insbesondere der Nachweis von Autoantikörpern gegen AQP4 (AQP4-Antikörper, NMO-IgG). AQP4-Antikörper können im Serum bei über $80 \%$ der NMO-Patienten nachgewiesen werden.

- Das Zielantigen des Autoantikörpers, das Wasserkanalprotein AQP4, wird ubiquitär im zentralen Nervensystem, jedoch in höchsten Konzentrationen in den Endfüßchen von Astrozyten der Glia limitans interna und externa exprimiert. Es bildet in dieser Lokalisation einen wichtigen Bestandteil der Blut-HirnSchranke.

- Neben den beiden Indexmanifestationen Optikusneuritis und Myelitis kommen häufig auch Hirnstamm- und Dienzephalitiden vor. Als besonders charakteristisch gilt das Area-postrema-Syndrom, das durch entzündliche Läsionen in der dorsalen Medulla verursacht wird und durch unstillbaren Schluckauf und/oder unstillbares Erbrechen gekennzeichnet ist.

- Die klinischen Symptome der NMO treten meist schubförmig auf; bei AQP4-IgG-negativen Patienten verläuft die Erkrankung selten auch monophasisch.

- Akute Schübe werden mit hochdosierten intravenösen Steroiden und/oder Plasmapherese behandelt. Zur Rezidivprophylaxe ist eine Therapie mit Immunsuppressiva oder B-Zelldepletierenden Therapien essenziell.

\section{Schlüsselwörter}

Neuromyelitis optica, Autoimmunerkrankung, Neuromyelitis, Sehnerv, Aquaporin-4

Interessenkonflikt

Die Autoren geben an, dass kein Interessenkonflikt besteht. 


\section{Korrespondenzadresse}

Dr. Florence Pache

Charité Universitätsmedizin Berlin

NeuroCure Clinical Research Center und

Klinisches und Experimentelles Forschungszentrum

für Multiple Sklerose

Klinik für Neurologie

Charitéplatz 1

10117 Berlin

Tel.: ++ 49/30/450660330

Fax: ++ 49/30/4507660330

E-Mail: florence.pache@charite.de

Wissenschaftlich verantwortlich gemäß Zertifizierungsbestimmungen

Wissenschaftlich verantwortlich gemäß Zertifizierungsbestimmungen für diesen Beitrag ist Professor Dr. med. Michael Forsting, Universitätsklinikum Essen.

\section{Erstveröffentlichung und Erratum}

Dieser Artikel wurde in Fortschr Neurol Psychiatr 2017; 85: 100-114 erstveröffentlicht. Erratum: Im Beitrag „Neuromyelitis optica“" (Fortschr Neurol Psychiatr 2017; 85: $100-$ 114) befand sich im englischen Abstract ein Komma zwischen „(CNS)“ und „that", das gelöscht wurde.

Literatur

[1] Trebst C, Jarius S, Berthele A et al. Update on the diagnosis and treatment of neuromyelitis optica: recommendations of the Neuromyelitis Optica Study Group (NEMOS). J Neurol 2014; $261: 1-16$

[2] Jarius S, Wildemann B, Paul F. Neuromyelitis optica: clinical features, immunopathogenesis and treatment. Clin Exp Immunol 2014; 176: 149-164

[3] Jarius S, Ruprecht K, Wildemann B et al. Contrasting disease patterns in seropositive and seronegative neuromyelitis optica: a multicentre study of 175 patients. J Neuroinflammation 2012; 9: 14

[4] Kim H], Paul F, Lana-Peixoto MA et al. MRI characteristics of neuromyelitis optica spectrum disorder: an international update. Neurology 2015; 84: 1165-1173

[5] Jarius S, Wildemann B. The history of neuromyelitis optica. J Neuroinflammation 2013; 10: 8

[6] Jacob A, Larner A]. Clifford Allbutt (1836-1925). J Neurol 2013; 260: 346-347

[7] Jarius S, Wildemann B. An early case of neuromyelitis optica: on a forgotten report by Jacob Lockhart Clarke, FRS. Mult Scler Houndmills Basingstoke Engl 2011; 17: 1384-1386

[8] Jarius S, Wildemann B. Devic's disease before Devic: bilateral optic neuritis and simultaneous myelitis in a young woman (1874). J Neurol Sci 2015; 358: 419-421

[9] Jarius S, Wildemann B. The case of the Marquis de Causan (1804): an early account of visual loss associated with spinal cord inflammation. J Neurol 2012; 259: 1354-1357
[10] Jarius S, Wildemann B. "Noteomielite" accompanied by acute amaurosis (1844). An early case of neuromyelitis optica. J Neurol Sci 2012; 313: $182-184$

[11] Jarius S, Wildemann B. On the contribution of Thomas Clifford Allbutt, F.R.S., to the early history of neuromyelitis optica. J Neurol 2013; 260: 100-104

[12] Jarius S, Wildemann B. "Spinal amaurosis" (1841). On the early contribution of Edward Hocken to the concept of neuromyelitis optica. J Neurol 2014; 261: 400 -404

[13] Jarius S, Wildemann B. An early British case of neuromyelitis optica (1850). BMJ 2012; 345: e6430

[14] Wingerchuk DM, Hogancamp WF, O'Brien PC et al. The clinical course of neuromyelitis optica (Devic's syndrome). Neurology 1999; 53: $1107-1114$

[15] Weinshenker BG, Wingerchuk DM, Vukusic $S$ et al. Neuromyelitis optica IgG predicts relapse after longitudinally extensive transverse myelitis. Ann Neurol 2006; 59: 566- 569

[16] Zekeridou A, Lennon VA. Aquaporin-4 autoimmunity. Neurol Neuroimmunol Neuroinflammation 2015; 2: e110

[17] Melamed E, Levy M, Waters PJ et al. Update on biomarkers in neuromyelitis optica. Neurol Neuroimmunol Neuroinflammation 2015; 2: e134

[18] Waters $P$, Jarius S, Littleton E et al. Aquaporin-4 antibodies in neuromyelitis optica and longitudinally extensive transverse myelitis. Arch Neurol 2008; 65: 913-919

[19] Jarius S, Franciotta D, Bergamaschi R et al. NMO-IgG in the diagnosis of neuromyelitis optica. Neurology 2007; 68: $1076-1077$

[20] Paul F, Jarius S, Aktas $O$ et al. Antibody to aquaporin 4 in the diagnosis of neuromyelitis optica. PLoS Med 2007; 4: e133

[21] Metz I, Beißbarth T, Ellenberger D et al. Serum peptide reactivities may distinguish neuromyelitis optica subgroups and multiple sclerosis. Neurol Neuroimmunol Neuroinflammation 2016; 3: e204

[22] Waters P, Reindl M, Saiz A et al. Multicentre comparison of a diagnostic assay: aquaporin-4 antibodies in neuromyelitis optica. J Neurol Neurosurg Psychiatry 2016; 87: 1005 - 1015

[23] Wingerchuk DM, Lennon VA, Pittock S] et al. Revised diagnostic criteria for neuromyelitis optica. Neurology 2006; 66: $1485-1489$

[24] Paty DW, Oger J], Kastrukoff LF et al. MRI in the diagnosis of MS: a prospective study with comparison of clinical evaluation, evoked potentials, oligoclonal banding, and CT. Neurology 1988; 38: $180-185$

[25] Wingerchuk DM, Lennon VA, Lucchinetti CF et al. The spectrum of neuromyelitis optica. Lancet Neurol 2007; 6: $805-815$

[26] Wingerchuk DM, Banwell B, Bennett JL et al. International consensus diagnostic criteria for neuromyelitis optica spectrum disorders. Neurology 2015; 85: 177-189

[27] Kister I, Paul F. Pushing the boundaries of neuromyelitis optica: Does antibody make the disease? Neurology 2015; 85 : $118-119$

[28] Wildemann B, Jarius S, Paul F. Neuromyelitis optica. Aktuelle Neurol 2012; 39: 33-41

[29] Flanagan EP, Cabre P, Weinshenker BG et al. Epidemiology of aquaporin-4 autoimmunity and neuromyelitis optica spectrum. Ann Neurol 2016: doi:10.1002/ana.24617

[30] Pandit L, Asgari N, Apiwattanakul M et al. Demographic and clinical features of neuromyelitis optica: a review. Mult Scler Houndmills Basingstoke Engl 2015; 21: 845-853 
[31] Weinshenker BG, Wingerchuk DM, Nakashima I et al. OSMS is NMO, but not MS: proven clinically and pathologically. Lancet Neurol 2006; 5: 110-111

[32] Sepúlveda M, Armangué T, Sola-Valls N et al. Neuromyelitis optica spectrum disorders: comparison according to the phenotype and serostatus. Neurol Neuroimmunol Neuroinflammation 2016; 3: e225

[33] Wingerchuk DM, Pittock SJ, Lucchinetti CF et al. A secondary progressive clinical course is uncommon in neuromyelitis optica. Neurology 2007; 68: 603-605

[34] Fujihara K, Nakashima I. Secondary progression and innate immunity in NMO: a possible link to alemtuzumab therapy? Neurol Neuroimmunol Neuroinflammation 2014; 1: e38

[35] Gelfand JM, Cotter J, Klingman J et al. Massive CNS monocytic infiltration at autopsy in an alemtuzumab-treated patient with NMO. Neurol Neuroimmunol Neuroinflammation 2014; 1: e34

[36] Krumbholz M, Hofstadt-van Oy U, Angstwurm K et al. Very late-onset neuromyelitis optica spectrum disorder beyond the age of 75. J Neurol 2015; 262: 1379-1384

[37] Borisow N, Kleiter I, Gahlen A et al. Influence of female sex and fertile age on neuromyelitis optica spectrum disorders. Mult Scler | 2017; 23: 1092 - 1103 doi:10.1177| 1352458516671203

[38] Jarius S, Paul F, Franciotta D et al. Neuromyelitis optica spectrum disorders in patients with myasthenia gravis: ten new aquaporin- 4 antibody positive cases and a review of the literature. Mult Scler Houndmills Basingstoke Engl 2012; 18 : $1135-1143$

[39] Leite MI, Coutinho E, Lana-Peixoto M et al. Myasthenia gravis and neuromyelitis optica spectrum disorder: a multicenter study of 16 patients. Neurology 2012; 78: 1601 1607

[40] Jarius S, Jacobi C, de Seze J et al. Frequency and syndrome specificity of antibodies to aquaporin- 4 in neurological patients with rheumatic disorders. Mult Scler Houndmills Basingstoke Engl 2011; 17: 1067-1073

[41] Popescu BFG, Lennon VA, Parisi JE et al. Neuromyelitis optica unique area postrema lesions: nausea, vomiting, and pathogenic implications. Neurology 2011; 76: 1229-1237

[42] Takahashi T, Miyazawa I, Misu T et al. Intractable hiccup and nausea in neuromyelitis optica with anti-aquaporin-4 antibody: a herald of acute exacerbations. J Neurol Neurosurg Psychiatry 2008; 79: 1075-1078

[43] Misu T, Fujihara K, Nakashima I et al. Intractable hiccup and nausea with periaqueductal lesions in neuromyelitis optica. Neurology 2005; 65: 1479-1482

[44] Apiwattanakul M, Popescu BF, Matiello M et al. Intractable vomiting as the initial presentation of neuromyelitis optica. Ann Neurol 2010; 68: 757-761

[45] Jarius S, Lauda F, Wildemann B et al. Steroid-responsive hearing impairment in NMO-lgG/aquaporin-4-antibody-positive neuromyelitis optica. J Neurol 2013; 260: 663-664

[46] Kremer L, Mealy M, Jacob A et al. Brainstem manifestations in neuromyelitis optica: a multicenter study of 258 patients. Mult Scler 2014; 20: $843-847$

[47] Schmidt F, Göktas O, Jarius S et al. Olfactory dysfunction in patients with neuromyelitis optica. Mult Scler Int 2013; 2013: 654501

[48] Baba T, Nakashima I, Kanbayashi T et al. Narcolepsy as an initial manifestation of neuromyelitis optica with anti-aquaporin-4 antibody. J Neurol 2009; 256: 287-288
[49] Nakajima H, Fujiki Y, Ito T et al. Anti-aquaporin-4 antibodypositive neuromyelitis optica presenting with syndrome of inappropriate antidiuretic hormone secretion as an initial manifestation. Case Rep Neurol 2011; 3: $263-267$

[50] Kravljanac R, Martinović V, Dujmović I et al. Relapsing inappropriate antidiuretic hormone secretion in an anti-aquaporin-4 antibody positive paediatric patient. Mult Scler Houndmills Basingstoke Engl 2014; 20: 1404 - 1406

[51] Bradl M, Kanamori Y, Nakashima I et al. Pain in neuromyelitis optica - prevalence, pathogenesis and therapy. Nat Rev Neurol 2014; 10: 529-536

[52] Chanson JB, Zéphir H, Collongues $\mathrm{N}$ et al. Evaluation of health-related quality of life, fatigue and depression in neuromyelitis optica. Eur J Neurol 2011; 18: 836-841

[53] Moore P, Methley A, Pollard C et al. Cognitive and psychiatric comorbidities in neuromyelitis optica. J Neurol Sci 2016; 360: $4-9$

[54] Mutch K, Zhao S, Hamid S et al. Bladder and bowel dysfunction affect quality of life. A cross sectional study of 60 patients with aquaporin- 4 antibody positive Neuromyelitis Optica spectrum disorder. Mult Scler Relat Disord 2015; 4: 614-618

[55] Zhao S, Mutch K, Elsone L et al. Neuropathic pain in neuromyelitis optica affects activities of daily living and quality of life. Mult Scler Houndmills Basingstoke Engl 2014; 20: $1658-1661$

[56] Akaishi T, Nakashima I, Misu T et al. Depressive state and chronic fatigue in multiple sclerosis and neuromyelitis optica. J Neuroimmunol 2015; 283: 70-73

[57] Zhang N, Li Y], Fu Y et al. Cognitive impairment in Chinese neuromyelitis optica. Mult Scler Houndmills Basingstoke Engl 2015; 21: $1839-1846$

[58] Song Y, Pan L, Fu Y et al. Sleep abnormality in neuromyelitis optica spectrum disorder. Neurol Neuroimmunol Neuroinflammation 2015; 2: e94

[59] Chavarro V, Mealy MA, Simpson A et al. Insufficient treatment of severe depression in neuromyelitis optica spectrum disorder. Neurol Neuroimmunol Neuroinflammation 2016; 3: e286

[60] Jarius S, Paul F, Franciotta D et al. Cerebrospinal fluid findings in aquaporin- 4 antibody positive neuromyelitis optica: results from 211 lumbar punctures. J Neurol Sci 2011; 306: $82-90$

[61] Majed M, Fryer JP, McKeon A et al. Clinical utility of testing AQP4-IgG in CSF: guidance for physicians. Neurol Neuroimmunol Neuroinflammation 2016; 3: e231

[62] Jarius S, Wildemann B. Effect of storage conditions and freeze/thaw cycles on aquaporin-4 antibody (NMO-lgG) serum levels. Clin Chem Lab Med 2011; 49: 2121-2122

[63] Jarius S, Franciotta D, Paul F et al. Cerebrospinal fluid antibodies to aquaporin-4 in neuromyelitis optica and related disorders: frequency, origin, and diagnostic relevance. J Neuroinflammation 2010; 7: 52

[64] Jarius S, Franciotta D, Bergamaschi R et al. Immunoglobulin $M$ antibodies to aquaporin-4 in neuromyelitis optica and related disorders. Clin Chem Lab Med 2010; 48: 659-663

[65] Jarius S, Paul F, Fechner K et al. Aquaporin-4 antibody testing: direct comparison of M1-AQP4-DNA-transfected cells with leaky scanning versus M23-AQP4-DNA-transfected cells as antigenic substrate. J Neuroinflammation 2014; 11 : 129 
[66] Jarius S, Wildemann B. AQP4 antibodies in neuromyelitis optica: diagnostic and pathogenetic relevance. Nat Rev Neurol 2010; 6: 383-392

[67] Jarius S, Wildemann B. Aquaporin-4 antibodies (NMO-lgG) as a serological marker of neuromyelitis optica: a critical review of the literature. Brain Pathol Zurich Switz 2013; 23: $661-683$

[68] Jarius S, Franciotta D, Paul F et al. Testing for antibodies to human aquaporin-4 by ELISA: sensitivity, specificity, and direct comparison with immunohistochemistry. J Neurol Sci 2012; 320: $32-37$

[69] Jarius S, Ruprecht K, Kleiter I et al. MOG-IgG in NMO and related disorders: a multicenter study. Part 1: Frequency, syndrome specificity, influence of disease activity, longterm course, association with AQP4-IgG, and origin. J Neuroinflammation 2016; 13: 279

[70] Reindl M, Rostasy K. MOG antibody-associated diseases. Neurol Neuroimmunol Neuroinflammation 2015; 2: e60

[71] Chalmoukou K, Alexopoulos H, Akrivou S et al. Anti-MOG antibodies are frequently associated with steroid-sensitive recurrent optic neuritis. Neurol Neuroimmunol Neuroinflammation 2015; 2: e131

[72] Waters P, Woodhall M, O'Connor KC et al. MOG cell-based assay detects non-MS patients with inflammatory neurologic disease. Neurol Neuroimmunol Neuroinflammation 2015; 2: e89

[73] Ramanathan S, Prelog K, Barnes EH et al. Radiological differentiation of optic neuritis with myelin oligodendrocyte glycoprotein antibodies, aquaporin-4 antibodies, and multiple sclerosis. Mult Scler Houndmills Basingstoke Engl 2016; 22: $470-482$

[74] Zamvil SS, Slavin AJ. Does MOG Ig-positive AQP4-seronegative opticospinal inflammatory disease justify a diagnosis of NMO spectrum disorder? Neurol Neuroimmunol Neuroinflammation 2015; 2: e62

[75] Kim SM, Woodhall MR, Kim JS et al. Antibodies to MOG in adults with inflammatory demyelinating disease of the CNS. Neurol Neuroimmunol Neuroinflammation 2015; 2: e163

[76] Jarius S, Ruprecht K, Kleiter I et al. MOG-IgG in NMO and related disorders: a multicenter study. Part 2: Epidemiology, clinical presentation, radiological and laboratory features, treatment, and long-term outcome. J Neuroinflammation 2016; 13: 280

[77] Jarius S, Kleiter I, Ruprecht K et al. MOG-IgG in NMO and related disorders: a multicenter study. Part 3: MOG-IgGassociated brainstem encephalitis. J Neuroinflammation 2016; 13: 281

[78] Pache F, Zimmermann H, Mikolajczak J et al. MOG-IgG in NMO and related disorders: a multicenter study. Part 4: Afferent visual system damage after optic neuritis in MOGIgG-seropositive versus AQP4-IgG-seropositive patients. J Neuroinflammation 2016; 13: 282

[79] Mader S, Gredler V, Schanda K et al. Complement activating antibodies to myelin oligodendrocyte glycoprotein in neuromyelitis optica and related disorders. J Neuroinflammation 2011; 8: 184

[80] Spadaro M, Gerdes LA, Krumbholz M et al. Autoantibodies to MOG in a distinct subgroup of adult multiple sclerosis. Neurol Neuroimmunol Neuroinflammation 2016; 3: e257

[81] Woodhall M, Çoban A, Waters P et al. Glycine receptor and myelin oligodendrocyte glycoprotein antibodies in Turkish patients with neuromyelitis optica. J Neurol Sci 2013; 335: $221-223$
[82] Jarius S, Aboul-Enein F, Waters $P$ et al. Antibody to aquaporin-4 in the long-term course of neuromyelitis optica. Brain J Neurol 2008; 131: $3072-3080$

[83] Kidd DP, Burton B], Graham EM et al. Optic neuropathy associated with systemic sarcoidosis. Neurol Neuroimmunol Neuroinflammation 2016; 3: e270

[84] Jarius S, Paul F, Ruprecht K et al. Low vitamin B12 levels and gastric parietal cell antibodies in patients with aquaporin-4 antibody-positive neuromyelitis optica spectrum disorders. J Neurol 2012; 259: $2743-2745$

[85] Kimbrough DJ, Mealy MA, Simpson A et al. Predictors of recurrence following an initial episode of transverse myelitis. Neurol Neuroimmunol Neuroinflammation 2014; 1: e4

[86] Jarius S, Franciotta D, Bergamaschi R et al. Polyspecific, antiviral immune response distinguishes multiple sclerosis and neuromyelitis optica. J Neurol Neurosurg Psychiatry 2008; 79: $1134-1136$

[87] Jarius S, Eichhorn P, Franciotta D et al. The MRZ reaction as a highly specific marker of multiple sclerosis: re-evaluation and structured review of the literature. J Neurol 2016: doi:10.1007/s00415-016-8360-4

[88] Pekcevik Y, Mitchell CH, Mealy MA et al. Differentiating neuromyelitis optica from other causes of longitudinally extensive transverse myelitis on spinal magnetic resonance imaging. Mult Scler Houndmills Basingstoke Engl 2016; 22: $302-311$

[89] Yonezu T, Ito S, Mori M et al. "Bright spotty lesions" on spinal magnetic resonance imaging differentiate neuromyelitis optica from multiple sclerosis. Mult Scler Houndmills Basingstoke Engl 2014; 20: 331 - 337

[90] Asgari N, Skejoe HPB, Lennon VA. Evolution of longitudinally extensive transverse myelitis in an aquaporin-4 IgG-positive patient. Neurology 2013; 81: 95-96

[91] Flanagan EP, Weinshenker BG, Krecke KN et al. Short myelitis lesions in aquaporin-4-IgG-positive neuromyelitis optica spectrum disorders. JAMA Neurol 2015; 72: $81-87$

[92] Ventura RE, Kister I, Chung $S$ et al. Cervical spinal cord atrophy in NMOSD without a history of myelitis or MRI-visible lesions. Neurol Neuroimmunol Neuroinflammation 2016; 3: e224

[93] Ito S, Mori M, Makino T et al. "Cloud-like enhancement" is a magnetic resonance imaging abnormality specific to neuromyelitis optica. Ann Neurol 2009; 66: 425-428

[94] Banker P, Sonni S, Kister I et al. Pencil-thin ependymal enhancement in neuromyelitis optica spectrum disorders. Mult Scler Houndmills Basingstoke Engl 2012; 18: 1050 1053

[95] Sinnecker T, Dörr J, Pfueller CF et al. Distinct lesion morphology at 7-T MRI differentiates neuromyelitis optica from multiple sclerosis. Neurology 2012; 79: $708-714$

[96] Kister I, Herbert J, Zhou Y et al. Ultrahigh-field MR (7 T) imaging of brain lesions in neuromyelitis optica. Mult Scler Int 2013; 2013: 398259

[97] Pache F, Zimmermann H, Finke C et al. Brain parenchymal damage in neuromyelitis optica spectrum disorder - a multimodal MRI study. Eur Radiol 2016; 26: 4413-4422

[98] Finke C, Heine J, Pache F et al. Normal volumes and microstructural integrity of deep gray matter structures in AQP4+ NMOSD. Neurol Neuroimmunol Neuroinflammation 2016: 3: e229

[99] Matthews L, Marasco R, Jenkinson M et al. Distinction of seropositive NMO spectrum disorder and MS brain lesion distribution. Neurology 2013; 80: 1330-1337 
[100] Kremer S, Renard F, Achard S et al. Use of advanced magnetic resonance imaging techniques in neuromyelitis optica spectrum disorder. JAMA Neurol 2015; 72: 815-822

[101] Ringelstein M, Kleiter I, Ayzenberg I et al. Visual evoked potentials in neuromyelitis optica and its spectrum disorders. Mult Scler Houndmills Basingstoke Engl 2014; 20: $617-620$

[102] Brandt AU, Oberwahrenbrock T, Ringelstein M et al. Primary retinal pathology in multiple sclerosis as detected by optical coherence tomography. Brain J Neurol 2011; 134: e193; author reply e194

[103] Bock M, Paul F, Dörr J. Diagnosis and monitoring of multiple sclerosis: the value of optical coherence tomography. Nervenarzt 2013; 84: 483-492

[104] Bock M, Brandt AU, Kuchenbecker J et al. Impairment of contrast visual acuity as a functional correlate of retinal nerve fibre layer thinning and total macular volume reduction in multiple sclerosis. $\mathrm{Br}$ J Ophthalmol 2012; 96: $62-67$

[105] Pfueller CF, Brandt AU, Schubert F et al. Metabolic changes in the visual cortex are linked to retinal nerve fiber layer thinning in multiple sclerosis. PloS One 2011; 6: e18019

[106] Kaufhold F, Zimmermann H, Schneider E et al. Optic neuritis is associated with inner nuclear layer thickening and microcystic macular edema independently of multiple sclerosis. PloS One 2013; 8: e71145

[107] Brandt AU, Oberwahrenbrock T, Kadas EM et al. Dynamic formation of macular microcysts independent of vitreous traction changes. Neurology 2014; 83: $73-77$

[108] Schneider E, Zimmermann H, Oberwahrenbrock T et al. Optical coherence tomography reveals distinct patterns of retinal damage in neuromyelitis optica and multiple sclerosis. PloS One 2013; 8: e66151

[109] Bennett JL, de Seze J, Lana-Peixoto M et al. Neuromyelitis optica and multiple sclerosis: seeing differences through optical coherence tomography. Mult Scler Houndmills Basingstoke Engl 2015; 21: 678-688

[110] Petzold A, Wattjes MP, Costello F et al. The investigation of acute optic neuritis: a review and proposed protocol. Nat Rev Neurol 2014; 10: 447-458

[111] Baumann M, Sahin K, Lechner C et al. Clinical and neuroradiological differences of paediatric acute disseminating encephalomyelitis with and without antibodies to the myelin oligodendrocyte glycoprotein. J Neurol Neurosurg Psychiatry 2015; 86: 265-272

[112] Rostasy K, Reindl M. Role of autoantibodies in acquired inflammatory demyelinating diseases of the central nervous system in children. Neuropediatrics 2013; 44: 297-301

[113] Flanagan EP, Kaufmann T], Krecke KN et al. Discriminating long myelitis of neuromyelitis optica from sarcoidosis. Ann Neurol 2016; 79: 437-447

[114] Trebst C, Raab P, Voss EV et al. Longitudinal extensive transverse myelitis - it's not all neuromyelitis optica. Nat Rev Neurol 2011; 7: 688-698

[115] Kitley JL, Leite MI, George JS et al. The differential diagnosis of longitudinally extensive transverse myelitis. Mult Scler Houndmills Basingstoke Engl 2012; 18: 271 - 285

[116] Iyer A, Elsone L, Appleton R et al. A review of the current literature and a guide to the early diagnosis of autoimmune disorders associated with neuromyelitis optica. Autoimmunity 2014; 47: $154-161$

[117] Jaiser SR, Winston GP. Copper deficiency myelopathy. J Neurol 2010; 257: 869-881
[118] Ringelstein M, Metz I, Ruprecht K et al. Contribution of spinal cord biopsy to diagnosis of aquaporin-4 antibody positive neuromyelitis optica spectrum disorder. Mult Scler Houndmills Basingstoke Engl 2014; 20: 882-888

[119] Ringelstein M, Aktas O, Harmel J et al. Contribution of spinal cord biopsy to the differential diagnosis of longitudinal extensive transverse myelitis. Nervenarzt 2014; 85: 1298 1303

[120] Pröbstel AK, Rudolf G, Dornmair K et al. Anti-MOG antibodies are present in a subgroup of patients with a neuromyelitis optica phenotype. J Neuroinflammation 2015; 12 : 46

[121] Galetta SL, Villoslada P, Levin N et al. Acute optic neuritis: unmet clinical needs and model for new therapies. Neurol Neuroimmunol Neuroinflammation 2015; 2: e135

[122] Petzold A, Plant GT. Diagnosis and classification of autoimmune optic neuropathy. Autoimmun Rev 2014; 13 : $539-545$

[123] Matiello M, Lennon VA, Jacob A et al. NMO-IgG predicts the outcome of recurrent optic neuritis. Neurology 2008; 70: $2197-2200$

[124] Jarius S, Frederikson J, Waters P et al. Frequency and prognostic impact of antibodies to aquaporin- 4 in patients with optic neuritis. J Neurol Sci 2010; 298: 158-162

[125] Jarius S, Probst C, Borowski K et al. Standardized method for the detection of antibodies to aquaporin-4 based on a highly sensitive immunofluorescence assay employing recombinant target antigen. J Neurol Sci 2010; 291: 52-56

[126] Jarius S, Eichhorn P, Jacobi C et al. The intrathecal, polyspecific antiviral immune response: specific for MS or a general marker of CNS autoimmunity? J Neurol Sci 2009; 280: $98-100$

[127] Petereit HF, Reske D, Tumani H et al. Soluble CSF interleukin 2 receptor as indicator of neurosarcoidosis. J Neurol 2010; 257: $1855-1863$

[128] Jarius S, Wandinger KP, Borowski K et al. Antibodies to CV2/CRMP5 in neuromyelitis optica-like disease: case report and review of the literature. Clin Neurol Neurosurg 2012; 114: 331-335

[129] Mitsdoerffer M, Kuchroo V, Korn T. Immunology of neuromyelitis optica: a T cell-B cell collaboration. Ann N Y Acad Sci 2013; 1283: 57-66

[130] Jarius S, Paul F, Franciotta D et al. Mechanisms of disease: aquaporin-4 antibodies in neuromyelitis optica. Nat Clin Pract Neurol 2008; 4: $202-214$

[131] Levy M, Wildemann B, Jarius S et al. Immunopathogenesis of neuromyelitis optica. Adv Immunol 2014; 121: 213 242

[132] Lennon VA, Kryzer T], Pittock S] et al. IgG marker of opticspinal multiple sclerosis binds to the aquaporin- 4 water channel. J Exp Med 2005; 202: 473-477

[133] Papadopoulos MC, Verkman AS. Aquaporin water channels in the nervous system. Nat Rev Neurosci 2013; 14: 265 277

[134] Lucchinetti CF, Mandler RN, McGavern D et al. A role for humoral mechanisms in the pathogenesis of Devic's neuromyelitis optica. Brain J Neurol 2002; 125: 1450 - 1461

[135] Misu T, Fujihara K, Kakita A et al. Loss of aquaporin 4 in lesions of neuromyelitis optica: distinction from multiple sclerosis. Brain J Neurol 2007; 130: 1224-1234

[136] Roemer SF, Parisi JE, Lennon VA et al. Pattern-specific loss of aquaporin-4 immunoreactivity distinguishes neuromy- 
elitis optica from multiple sclerosis. Brain J Neurol 2007; 130: $1194-1205$

[137] Sinclair C, Kirk J, Herron B et al. Absence of aquaporin-4 expression in lesions of neuromyelitis optica but increased expression in multiple sclerosis lesions and normal-appearing white matter. Acta Neuropathol (Berl) 2007; 113: $187-194$

[138] Saadoun S, Waters P, Bell BA et al. Intra-cerebral injection of neuromyelitis optica immunoglobulin $G$ and human complement produces neuromyelitis optica lesions in mice. Brain J Neurol 2010; 133: 349-361

[139] Kim W, Lee JE, Li XF et al. Quantitative measurement of anti-aquaporin-4 antibodies by enzyme-linked immunosorbent assay using purified recombinant human aquaporin-4. Mult Scler Houndmills Basingstoke Engl 2012; 18: $578-586$

[140] Chihara N, Aranami T, Sato W et al. Interleukin 6 signaling promotes anti-aquaporin 4 autoantibody production from plasmablasts in neuromyelitis optica. Proc Natl Acad Sci U S A 2011; 108: 3701 - 3706

[141] Takahashi T, Fujihara K, Nakashima I et al. Anti-aquaporin4 antibody is involved in the pathogenesis of NMO: a study on antibody titre. Brain J Neurol 2007; 130: $1235-1243$

[142] Bedi GS, Brown AD, Delgado SR et al. Impact of rituximab on relapse rate and disability in neuromyelitis optica. Mult Scler Houndmills Basingstoke Engl 2011; 17: 1225-1230

[143] Kim SH, Huh SY, Lee S] et al. A 5-year follow-up of rituximab treatment in patients with neuromyelitis optica spectrum disorder. JAMA Neurol 2013; 70: 1110-1117

[144] Pellkofer HL, Krumbholz M, Berthele A et al. Long-term follow-up of patients with neuromyelitis optica after repeated therapy with rituximab. Neurology 2011; 76 : $1310-1315$

[145] Harmel J, Ringelstein M, Ingwersen J et al. Interferon- $\beta$ related tumefactive brain lesion in a Caucasian patient with neuromyelitis optica and clinical stabilization with tocilizumab. BMC Neurol 2014; 14: 247

[146] Araki M, Matsuoka T, Miyamoto K et al. Efficacy of the antiIL-6 receptor antibody tocilizumab in neuromyelitis optica: a pilot study. Neurology 2014; 82: $1302-1306$

[147] Ayzenberg I, Kleiter I, Schröder A et al. Interleukin 6 receptor blockade in patients with neuromyelitis optica nonresponsive to anti-CD20 therapy. JAMA Neurol 2013; 70: $394-397$

[148] Kieseier BC, Stüve O, Dehmel T et al. Disease amelioration with tocilizumab in a treatment-resistant patient with neuromyelitis optica: implication for cellular immune responses. JAMA Neurol 2013; 70: 390-393

[149] Ringelstein M, Ayzenberg I, Harmel ] et al. Long-term therapy with interleukin 6 receptor blockade in highly active neuromyelitis optica spectrum disorder. JAMA Neurol 2015; 72: $756-763$

[150] Khatri BO, Kram J, Dukic M et al. Maintenance plasma exchange therapy for steroid-refractory neuromyelitis optica. J Clin Apheresis 2012; 27: 183-192

[151] Kim SH, Kim W, Huh SY et al. Clinical efficacy of plasmapheresis in patients with neuromyelitis optica spectrum disorder and effects on circulating anti-aquaporin-4 antibody levels. J Clin Neurol Seoul Korea 2013; 9: 36-42

[152] Merle H, Olindo S, Jeannin S et al. Treatment of optic neuritis by plasma exchange (add-on) in neuromyelitis optica. Arch Ophthalmol Chic III 1960 2012; 130: 858-862

[153] Watanabe S, Nakashima I, Misu T et al. Therapeutic efficacy of plasma exchange in NMO-IgG-positive patients with neuromyelitis optica. Mult Scler Houndmills Basingstoke Engl 2007; 13: $128-132$

[154] Bonnan M, Valentino R, Olindo S et al. Plasma exchange in severe spinal attacks associated with neuromyelitis optica spectrum disorder. Mult Scler Houndmills Basingstoke Engl 2009; 15: 487-492

[155] Matiello M, Schaefer-Klein J, Sun D et al. Aquaporin 4 expression and tissue susceptibility to neuromyelitis optica. JAMA Neurol 2013; 70: 1118-1125

[156] Isobe N, Yonekawa T, Matsushita T et al. Quantitative assays for anti-aquaporin-4 antibody with subclass analysis in neuromyelitis optica. Mult Scler Houndmills Basingstoke Engl 2012; 18: $1541-1551$

[157] Jarius S, Jacob S, Leite M et al. NMO-IgG/Aqp4-Ab belongs to the $\operatorname{lgG} 1$ subclass and activates complement in vitro. London: Sage publication Ltd; 2007: S159-S159

[158] Kalluri SR, Illes Z, Srivastava R et al. Quantification and functional characterization of antibodies to native aquaporin 4 in neuromyelitis optica. Arch Neurol 2010; 67: $1201-1208$

[159] Misu T, Höftberger R, Fujihara K et al. Presence of six different lesion types suggests diverse mechanisms of tissue injury in neuromyelitis optica. Acta Neuropathol (Berl) 2013; 125: 815-827

[160] Kuroda H, Fujihara K, Takano R et al. Increase of complement fragment $\mathrm{C} 5 \mathrm{a}$ in cerebrospinal fluid during exacerbation of neuromyelitis optica. J Neuroimmunol 2013; 254: $178-182$

[161] Pittock S], Lennon VA, McKeon A et al. Eculizumab in AQP4-IgG-positive relapsing neuromyelitis optica spectrum disorders: an open-label pilot study. Lancet Neurol 2013; $12: 554-562$

[162] Paul F. Hope for a rare disease: eculizumab in neuromyelitis optica. Lancet Neurol 2013; 12: 529-531

[163] Quan C, Yu H, Qiao J et al. Impaired regulatory function and enhanced intrathecal activation of B cells in neuromyelitis optica: distinct from multiple sclerosis. Mult Scler Houndmills Basingstoke Engl 2013; 19: 289-298

[164] Quan C, ZhangBao J, Lu J et al. The immune balance between memory and regulatory B cells in NMO and the changes of the balance after methylprednisolone or rituximab therapy. J Neuroimmunol 2015; 282: 45-53

[165] Wang H, Wang K, Zhong X et al. Cerebrospinal fluid BAFF and APRIL levels in neuromyelitis optica and multiple sclerosis patients during relapse. J Clin Immunol 2012; 32: $1007-1011$

[166] Vaknin-Dembinsky A, Brill L, Orpaz N et al. Preferential increase of B-cell activating factor in the cerebrospinal fluid of neuromyelitis optica in a white population. Mult Scler Houndmills Basingstoke Engl 2010; 16: 1453 - 1457

[167] Takeshita Y, Obermeier B, Cotleur AC et al. Effects of neuromyelitis optica-lgG at the blood-brain barrier in vitro. Neurol Neuroimmunol Neuroinflammation 2017; 4: e311

[168] Ratelade J, Bennett JL, Verkman AS. Evidence against cellular internalization in vivo of $\mathrm{NMO}-\mathrm{lgG}$, aquaporin-4, and excitatory amino acid transporter 2 in neuromyelitis optica. J Biol Chem 2011; 286: 45156 - 45164

[169] Hinson SR, Roemer SF, Lucchinetti CF et al. Aquaporin-4binding autoantibodies in patients with neuromyelitis optica impair glutamate transport by down-regulating EAAT2. J Exp Med 2008; 205: 2473-2481 
[170] Alberdi E, Sánchez-Gómez MV, Torre I et al. Activation of kainate receptors sensitizes oligodendrocytes to complement attack. J Neurosci Off J Soc Neurosci 2006; 26: $3220-3228$

[171] Titulaer M], Höftberger R, lizuka T et al. Overlapping demyelinating syndromes and anti- $\mathrm{N}$-methyl-D-aspartate receptor encephalitis. Ann Neurol 2014; 75: 411-428

[172] Zeka B, Hastermann M, Hochmeister S et al. Highly encephalitogenic aquaporin 4-specific T cells and NMO-IgG jointly orchestrate lesion location and tissue damage in the CNS. Acta Neuropathol (Berl) 2015; 130: $783-798$

[173] Hertwig L, Pache F, Romero-Suarez S et al. Distinct functionality of neutrophils in multiple sclerosis and neuromyelitis optica. Mult Scler Houndmills Basingstoke Engl 2016; $22: 160-173$

[174] Hiepe F, Dörner T, Hauser AE et al. Long-lived autoreactive plasma cells drive persistent autoimmune inflammation. Nat Rev Rheumatol 2011; 7: 170-178

[175] Collongues N, de Seze J. Current and future treatment approaches for neuromyelitis optica. Ther Adv Neurol Disord 2011; 4: $111-121$

[176] Sellner J, Boggild M, Clanet M et al. EFNS guidelines on diagnosis and management of neuromyelitis optica. Eur J Neurol Off J Eur Fed Neurol Soc 2010; 17: 1019-1032

[177] Kimbrough DJ, Fujihara K, Jacob A et al. Treatment of neuromyelitis optica: review and recommendations. Mult Scler Relat Disord 2012; 1: 180 - 187

[178] Trebst C, Berthele A, Jarius S et al. Diagnosis and treatment of neuromyelitis optica. Consensus recommendations of the Neuromyelitis Optica Study Group. Nervenarzt 2011; 82: $768-777$

[179] Kleiter I, Gold R. Present and future therapies in neuromyelitis optica spectrum disorders. Neurother J Am Soc Exp Neurother 2016; 13: $70-83$

[180] Yamasaki R, Matsushita T, Fukazawa T et al. Efficacy of intravenous methylprednisolone pulse therapy in patients with multiple sclerosis and neuromyelitis optica. Mult Scler Houndmills Basingstoke Engl 2016; 22: 1337 - 1348

[181] Wingerchuk DM, Weinshenker BG. Neuromyelitis optica. Curr Treat Options Neurol 2008; 10: 55-66

[182] Papadopoulos MC, Bennett JL, Verkman AS. Treatment of neuromyelitis optica: state-of-the-art and emerging therapies. Nat Rev Neurol 2014; 10: 493-506

[183] Abboud H, Petrak A, Mealy M et al. Treatment of acute relapses in neuromyelitis optica: steroids alone versus steroids plus plasma exchange. Mult Scler Houndmills Basingstoke Engl 2016; 22: 185-192

[184] Bonnan M, Cabre P. Plasma exchange in severe attacks of neuromyelitis optica. Mult Scler Int 2012 2012: 787630

[185] Kleiter I, Gahlen A, Borisow N et al. Neuromyelitis optica: evaluation of 871 attacks and 1153 treatment courses. Ann Neurol 2016; 79: 206-216

[186] Kleiter I, Hellwig K, Berthele A et al. Failure of natalizumab to prevent relapses in neuromyelitis optica. Arch Neurol 2012; 69: 239-245

[187] Jacob A, Hutchinson M, Elsone L et al. Does natalizumab therapy worsen neuromyelitis optica? Neurology 2012; 79 : $1065-1066$

[188] Kitley J, Evangelou N, Küker W et al. Catastrophic brain relapse in seronegative NMO after a single dose of natalizumab. J Neurol Sci 2014; 339: 223-225

[189] Ayzenberg I, Schöllhammer ], Hoepner R et al. Efficacy of glatiramer acetate in neuromyelitis optica spectrum dis- order: a multicenter retrospective study. J Neurol 2016; 263: $575-582$

[190] Min JH, Kim B], Lee KH. Development of extensive brain lesions following fingolimod (FTY720) treatment in a patient with neuromyelitis optica spectrum disorder. Mult Scler Houndmills Basingstoke Engl 2012; 18: 113-115

[191] Azzopardi L, Cox AL, McCarthy CL et al. Alemtuzumab use in neuromyelitis optica spectrum disorders: a brief case series. J Neurol 2016; 263: 25-29

[192] Kim SH, Huh SY, Kim W et al. Clinical characteristics and outcome of multiple sclerosis in Korea: Does multiple sclerosis in Korea really differ from that in the Caucasian populations? Mult Scler Houndmills Basingstoke Engl 2013; 19: $1493-1498$

[193] Carroll WM, Saida T, Kim HJ et al. A guide to facilitate the early treatment of patients with idiopathic demyelinating disease (multiple sclerosis and neuromyelitis optica). Mult Scler Houndmills Basingstoke Engl 2013; 19: 1371 - 1380

[194] Jarernsook B, Siritho S, Prayoonwiwat N. Efficacy and safety of beta-interferon in Thai patients with demyelinating diseases. Mult Scler Houndmills Basingstoke Engl 2013; 19: 585-592

[195] Kornberg MD, Newsome SD. Unmasking and provoking severe disease activity in a patient with NMO spectrum disorder. Neurol Neuroimmunol Neuroinflammation 2015; 2: e66

[196] Elsone L, Kitley J, Luppe $S$ et al. Long-term efficacy, tolerability and retention rate of azathioprine in 103 aquaporin4 antibody-positive neuromyelitis optica spectrum disorder patients: a multicentre retrospective observational study from the UK. Mult Scler Houndmills Basingstoke Engl 2014; 20: $1533-1540$

[197] Costanzi C, Matiello M, Lucchinetti CF et al. Azathioprine: tolerability, efficacy, and predictors of benefit in neuromyelitis optica. Neurology 2011; 77: 659-666

[198] Mealy MA, Wingerchuk DM, Palace J et al. Comparison of relapse and treatment failure rates among patients with neuromyelitis optica: multicenter study of treatment efficacy. JAMA Neurol 2014; 71: 324-330

[199] Jeong IH, Park B, Kim SH et al. Comparative analysis of treatment outcomes in patients with neuromyelitis optica spectrum disorder using multifaceted endpoints. Mult Scler Houndmills Basingstoke Engl 2016; 22: 329-339

[200] Torres J, Pruitt A, Balcer L et al. Analysis of the treatment of neuromyelitis optica. J Neurol Sci 2015; 351: 31-35

[201] Nakashima I, Takahashi T, Cree BAC et al. Transient increases in anti-aquaporin- 4 antibody titers following rituximab treatment in neuromyelitis optica, in association with elevated serum BAFF levels. J Clin Neurosci Off J Neurosurg Soc Australas 2011; 18: 997 - 998

[202] Perumal JS, Kister I, Howard J et al. Disease exacerbation after rituximab induction in neuromyelitis optica. Neurol Neuroimmunol Neuroinflammation 2015; 2: e61

[203] Radaelli M, Moiola L, Sangalli F et al. Neuromyelitis optica spectrum disorders: long-term safety and efficacy of rituximab in Caucasian patients. Mult Scler Houndmills Basingstoke Engl 2016; 22: 511 - 519

[204] Jacob A, Matiello M, Weinshenker BG et al. Treatment of neuromyelitis optica with mycophenolate mofetil: retrospective analysis of 24 patients. Arch Neurol 2009; 66: $1128-1133$ 
[205] Huh SY, Kim SH, Hyun JW et al. Mycophenolate mofetil in the treatment of neuromyelitis optica spectrum disorder. JAMA Neurol 2014; 71: 1372-1378

[206] Neff RT, Hurst FP, Falta EM et al. Progressive multifocal leukoencephalopathy and use of mycophenolate mofetil after kidney transplantation. Transplantation 2008; 86: $1474-1478$

[207] Içöz S, Tüzün E, Kürtüncü M et al. Enhanced IL-6 production in aquaporin-4 antibody positive neuromyelitis optica patients. Int J Neurosci 2010; 120: 71 - 75

[208] Viswanathan S, Wong AHY, Quek AML et al. Intravenous immunoglobulin may reduce relapse frequency in neuromyelitis optica. J Neuroimmunol 2015; 282: $92-96$

[209] Elsone L, Panicker J, Mutch K et al. Role of intravenous immunoglobulin in the treatment of acute relapses of neuromyelitis optica: experience in 10 patients. Mult Scler Houndmills Basingstoke Engl 2014; 20: 501 - 504

[210] Dörr ], Bitsch A, Schmailzl KJG et al. Severe cardiac failure in a patient with multiple sclerosis following low-dose mitoxantrone treatment. Neurology 2009; 73: 991 - 993

[211] Paul F, Dörr ], Würfel J et al. Early mitoxantrone-induced cardiotoxicity in secondary progressive multiple sclerosis. J Neurol Neurosurg Psychiatry 2007; 78: $198-200$

[212] Stroet A, Hemmelmann C, Starck M et al. Incidence of therapy-related acute leukaemia in mitoxantrone-treated multiple sclerosis patients in Germany. Ther Adv Neurol Disord 2012; 5: 75-79

[213] Buttmann M, Seuffert L, Mäder U et al. Malignancies after mitoxantrone for multiple sclerosis: a retrospective cohort study. Neurology 2016; 86: $2203-2207$

[214] Chanvillard C, Millward JM, Lozano M et al. Mitoxantrone induces natural killer cell maturation in patients with secondary progressive multiple sclerosis. PloS One 2012; 7: e39625

[215] Kim SH, Kim W, Park MS et al. Efficacy and safety of mitoxantrone in patients with highly relapsing neuromyelitis optica. Arch Neurol 2011; 68: 473-479

[216] Cabre P, Olindo S, Marignier R et al. Efficacy of mitoxantrone in neuromyelitis optica spectrum: clinical and neuroradiological study. J Neurol Neurosurg Psychiatry 2013; 84: $511-516$

[217] Weinstock-Guttman B, Ramanathan M, Lincoff $\mathrm{N}$ et al. Study of mitoxantrone for the treatment of recurrent neuromyelitis optica (Devic disease). Arch Neurol 2006; 63: 957-963

[218] Kitley J, Elsone L, George J et al. Methotrexate is an alternative to azathioprine in neuromyelitis optica spectrum disorders with aquaporin-4 antibodies. J Neurol Neurosurg Psychiatry 2013; 84: 918-921

[219] Ramanathan RS, Malhotra K, Scott T. Treatment of neuromyelitis optica/neuromyelitis optica spectrum disorders with methotrexate. BMC Neurol 2014; 14: 51

[220] Minagar A, Sheremata WA. Treatment of Devic's disease with methotrexate and prednisone. Int J MS Care 2000; 2: $43-49$

[221] Kageyama T, Komori M, Miyamoto K et al. Combination of cyclosporine A with corticosteroids is effective for the treatment of neuromyelitis optica. J Neurol 2013; 260: $627-634$

[222] Tanaka M, Kinoshita M, Tanaka K. Corticosteroid and tacrolimus treatment in neuromyelitis optica related disorders. Mult Scler Houndmills Basingstoke Engl 2015; 21: 669
[223] Bichuetti DB, Oliveira EML, Boulos F deC et al. Lack of response to pulse cyclophosphamide in neuromyelitis optica: evaluation of 7 patients. Arch Neurol 2012; 69: 938 939

[224] Cree BA, Bennett JL, Sheehan M et al. Placebo-controlled study in neuromyelitis optica - ethical and design considerations. Mult Scler Houndmills Basingstoke Engl 2016; 22: $862-872$

[225] Verkman AS, Phuan PW, Asavapanumas $N$ et al. Biology of AQP4 and anti-AQP4 antibody: therapeutic implications for NMO. Brain Pathol Zurich Switz 2013; 23: 684-695

[226] Mealy MA, Shin K, John G et al. Bevacizumab is safe in acute relapses of neuromyelitis optica. Clin Exp Neuroimmunol 2015; 6: 413-418

[227] Levy M, Mealy MA. Purified human C1-esterase inhibitor is safe in acute relapses of neuromyelitis optica. Neurol Neuroimmunol Neuroinflammation 2014; 1: e5

[228] Bourre B, Marignier R, Zéphir H et al. Neuromyelitis optica and pregnancy. Neurology 2012; 78: 875-879

[229] Fragoso YD, Adoni T, Bichuetti DB et al. Neuromyelitis optica and pregnancy. J Neurol 2013; 260: 2614-2619

[230] Reuss R, Rommer PS, Brück W et al. A woman with acute myelopathy in pregnancy: case outcome. BMJ 2009; 339: b4026

[231] Nour MM, Nakashima I, Coutinho E et al. Pregnancy outcomes in aquaporin-4-positive neuromyelitis optica spectrum disorder. Neurology 2016; 86: 79-87

[232] Saadoun S, Waters P, Leite MI et al. Neuromyelitis optica IgG causes placental inflammation and fetal death. J Immunol Baltim Md 1950 2013; 191: 2999-3005

[233] Davoudi V, Keyhanian K, Bove RM et al. Immunology of neuromyelitis optica during pregnancy. Neurol Neuroimmunol Neuroinflammation 2016; 3: e288

[234] Shimizu Y, Fujihara K, Ohashi T et al. Pregnancy-related relapse risk factors in women with anti-AQP4 antibody positivity and neuromyelitis optica spectrum disorder. Mult Scler Houndmills Basingstoke Engl 2016; 22: 1413 1420

[235] Greer IA, Nelson-Piercy C. Low-molecular-weight heparins for thromboprophylaxis and treatment of venous thromboembolism in pregnancy: a systematic review of safety and efficacy. Blood 2005; 106: 401-407

[236] Keeling D, Mackie I, Moore GW et al. Guidelines on the investigation and management of antiphospholipid syndrome. $\mathrm{Br}$ J Haematol 2012; 157: 47-58

[237] Empson M, Lassere M, Craig J et al. Prevention of recurrent miscarriage for women with antiphospholipid antibody or lupus anticoagulant. Cochrane Database Syst Rev 2005: CD002859

[238] Pharmakovigilanz- und Beratungszentrum für Embryonaltoxikologie der Charité-Universitätsmedizin Berlin. www. embryotox.de Im Internet: https://www.embryotox.de/ einfuehrung.html (Stand: 01.12.2017)

[239] Pellkofer HL, Suessmair C, Schulze A et al. Course of neuromyelitis optica during inadvertent pregnancy in a patient treated with rituximab. Mult Scler Houndmills Basingstoke Engl 2009; 15: 1006 - 1008

[240] Ringelstein M, Harmel J, Distelmaier F et al. Neuromyelitis optica and pregnancy during therapeutic $B$ cell depletion: infant exposure to anti-AQP4 antibody and prevention of rebound relapses with low-dose rituximab postpartum. 
Mult Scler Houndmills Basingstoke Engl 2013; 19: 1544 1547

[241] Collongues N, Marignier R, Jacob A et al. Characterization of neuromyelitis optica and neuromyelitis optica spectrum disorder patients with a late onset. Mult Scler Houndmills Basingstoke Engl 2013; 20: 1086-1094

[242] Tillema JM, McKeon A. The spectrum of neuromyelitis optica (NMO) in childhood. J Child Neurol 2012; 27: 1437 1447

[243] Wandinger KP, Stangel M, Witte T et al. Autoantibodies against aquaporin-4 in patients with neuropsychiatric systemic lupus erythematosus and primary Sjögren's syndrome. Arthritis Rheum 2010; 62: 1198-1200

[244] Závada J, Nytrová P, Wandinger KP et al. Seroprevalence and specificity of NMO-IgG (anti-aquaporin 4 antibodies) in patients with neuropsychiatric systemic lupus erythematosus. Rheumatol Int 2013; 33: 259-263

[245] Carvalho DC, Tironi TS, Freitas DS et al. Sjögren syndrome and neuromyelitis optica spectrum disorder co-exist in a common autoimmune milieu. Arq Neuropsiquiatr 2014; 72: 619-624

[246] Jayarangaiah A, Sehgal R, Epperla N. Sjögren's syndrome and neuromyelitis optica spectrum disorders (NMOSD) - a case report and review of literature. BMC Neurol 2014; 14 : 200

[247] Kolfenbach JR, Horner B], Ferucci ED et al. Neuromyelitis optica spectrum disorder in patients with connective tissue disease and myelitis. Arthritis Care Res 2011; 63: $1203-1208$

[248] Bergamaschi R, Jarius S, Robotti M et al. Two cases of benign neuromyelitis optica in patients with celiac disease. J Neurol 2009; 256: 2097-2099

[249] Jarius S, Jacob S, Waters P et al. Neuromyelitis optica in patients with gluten sensitivity associated with antibodies to aquaporin-4. J Neurol Neurosurg Psychiatry 2008; 79 : 1084
[250] Pittock SJ, Lennon VA, de Seze J et al. Neuromyelitis optica and non organ-specific autoimmunity. Arch Neurol 2008; 65: $78-83$

[251] Komai T, Shoda H, Yamaguchi K et al. Neuromyelitis optica spectrum disorder complicated with Sjogren syndrome successfully treated with tocilizumab: a case report. Mod Rheumatol Jpn Rheum Assoc 2016; 26: 294-296

[252] Ramanathan S, Reddel SW, Henderson A et al. Antibodies to myelin oligodendrocyte glycoprotein in bilateral and recurrent optic neuritis. Neurol Neuroimmunol Neuroinflammation 2014; 1: e40

[253] Hacohen Y, Absoud M, Deiva K et al. Myelin oligodendrocyte glycoprotein antibodies are associated with a non-MS course in children. Neurol Neuroimmunol Neuroinflammation 2015; 2: e81

[254] Kitley J, Waters P, Woodhall M et al. Neuromyelitis optica spectrum disorders with aquaporin-4 and myelin-oligodendrocyte glycoprotein antibodies: a comparative study. JAMA Neurol 2014; 71: 276-283

[255] Höftberger R, Sepulveda M, Armangue T et al. Antibodies to MOG and AQP4 in adults with neuromyelitis optica and suspected limited forms of the disease. Mult Scler Houndmills Basingstoke Engl 2015; 21: 866 - 874

[256] Di Pauli F, Höftberger R, Reindl M et al. Fulminant demyelinating encephalomyelitis: insights from antibody studies and neuropathology. Neurol Neuroimmunol Neuroinflammation 2015; 2: e175

[257] Neuromyelitis optica Studiengruppe. NEMOS. Im Internet: https://nemos-net.de/ (Stand: 01.12.2017)

\section{Bibliografie}

DOI https://doi.org/10.1055/a-0578-3693

Neuroradiologie Scan 2018; 08: 159-181

(c) Georg Thieme Verlag KG Stuttgart · New York ISSN 1616-9697 


\section{Punkte sammeln auf CME.thieme.de}

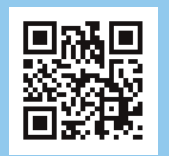

Diese Fortbildungseinheit ist 12 Monate online für die Teilnahme verfügbar.

Sollten Sie Fragen zur Online-Teilnahme haben, finden Sie unter http://cme.thieme.de/hilfe eine ausführliche Anleitung. Wir wünschen viel Erfolg beim Beantworten

der Fragen!

Unter https://eref.thieme.de/CXAL78Q oder über den QR-Code kommen Sie direkt zum Artikel zur Eingabe der Antworten.

VNR 2760512018154652408

\section{Frage 1}

Welche Aussage zu den AQP4-IgG-positiven Formen der Neuromyelitis optica trifft nicht zu?

A Sie unterscheiden sich hinsichtlich klinisch-radiologischer Parameter von den seronegativen Formen.

B Sie erfordern eine andere Therapie als seronegative Formen.

C Sie weisen eine einheitliche Pathophysiologie auf.

D Zu ihrem Nachweis muss eine akute Optikusneuritis gleichzeitig mit einer langstreckigen N.-opticus-Läsion oder Chiasmabeteiligung vorliegen.

E Sie können mit einer isolierten Optikusneuritis manifest werden.

\section{Frage 2}

Welche Aussage zur Serologie bei NMOSD ist falsch?

A Die AQP4-IgG-negative, aber MOG-IgG-positive Enzephalomyelitis ist immunpathologisch von der klassischen multiplen Sklerose abzugrenzen.

B Die Bestimmung der Antikörper gegen AQP4 erfolgt im Liquor.

C Seronegative Patienten sollten zum Ausschluss falschnegativer Befunde im späteren Krankheitsverlauf erneut serologisch getestet werden.

D Zur Antikörperbestimmung wird die Verwendung von ZBA empfohlen.

E Die Bestimmung von IgM-Antikörpern erhöht die Sensitivität der serologischen Untersuchung nicht.

\section{Frage 3}

Welcher der folgenden MRT-Befunde ist nicht typisch für NMOSD?

A Cloud-like Enhancement

B langstreckige T2w hyperintense Signalanhebungen über 3 oder mehr vertebrale Segmente

C Bright spotty Lesions

D Pencil-thin Enhancement

E Dawson-Finger

\section{Frage 4}

Weshalb kann eine NMOSD als ADEM fehlgedeutet werden?

A Bei ADEM können MOG-spezifische Antikörper im Serum nachgewiesen werden.

B Eine ADEM kann in Zusammenhang mit einer Infektion auftreten.

C Die ADEM manifestiert sich in Form von multifokalen und gleichzeitig Gehirn und Rückenmark betreffenden Demyelinisierungsherden.

D Die ADEM betrifft überwiegend Kinder.

E Eine ADEM kann als Reaktion auf eine Impfung auftreten.

\section{Frage 5}

Welcher der folgenden Befunde aus den Bereichen Klinik und Liquoruntersuchung gehört zu den Red Flags der NMOSD, also zu den Befunden, die eher gegen NMOSD sprechen?

A Zeitintervall von $4 \mathrm{~h}$ bis 4 Wochen bis zur maximalen Ausprägung der Symptome

B Krankheitsprogression ausschließlich während akuter Attacken

C oligoklonale Banden auch außerhalb eines akuten Schubes

D negative MRZ-Reaktion

E oligoklonale Banden nur während akuter Krankheitsschübe

\section{Frage 6}

Welcher Bestandteil des Immunsystems wird bei NMOSD supprimiert?

A Immunzellen (B-Zellen, T-Zellen, neutrophile und eosinophile Granulozyten sowie Makrophagen)

B AQP4-IgG

C Komplementsystem

D IL-10

E proinflammatorische Zytokine 


\section{Punkte sammeln auf CME.thieme.de}

Fortsetzung ...

\section{Frage 7}

Welche Aussage zur Plasmapherese bei NMOSD ist nicht korrekt?

A Sie wird bei unvollständiger Remission nach dem ersten Therapiezyklus mit Methylprednisolon eingesetzt.

B Sie dient der Antikörpereliminierung.

C Es werden meist 5-7 Zyklen mit Plasmaaustausch an jedem 2. Tag durchgeführt.

D Sie ist während der Schwangerschaft das Therapeutikum der Wahl.

E Sie ist sowohl für AQP4-IgG-seropositive als auch für AQP4-IgG-seronegative Patienten indiziert.

\section{Frage 8}

Welche Aussage zur Rezidivprophylaxe mit Azathioprin ist nicht zutreffend?

A Azathioprin muss stets in Kombination mit oralen Steroiden verabreicht werden.

B Bei langjähriger Anwendung von Azathioprin und sehr starker Immunsuppression steigt das Risiko insbesondere für Karzinome der Haut.

C Eine körpergewichtsadaptierte Dosierung scheint vorteilhaft zu sein.

D Azathioprin unterdrückt als Purinantimetabolit die Regeneration von Lymphozyten.

E Die Wirkung von Azathioprin entfaltet sich erst nach 3-6 Monaten.

\section{Frage 9}

Welche Aussage zu den Risiken einer Rezidivprophylaxe mit Rituximab ist nicht richtig?

A Latente Infektionen können durch Rituximab reaktiviert werden.

B Es kann eine allergische Reaktion auf Rituximab ausgelöst werden.

C Unter Rituximab-Therapie besteht eine erhöhte Fotosensibilität der Haut.

D Nach dem initialen Rituximab-Therapiezyklus können Krankheitsschübe vorkommen.

E Das immunologische Gedächtnis wird zum Zeitpunkt der ersten Rituximab-Infusion eingefroren, der Impfstatus muss also vorher überprüft und aufgefrischt werden.

\section{Frage 10}

Welche Substanz hat zur Rezidivprophylaxe während der Schwangerschaft ein eher günstiges Risikoprofil?
A Mycophenolatmofetil
B Prednisolon
C Rituximab
D Cyclophosphamid
E Azathioprin 